\title{
Proposta de novas unidades litoestratigráficas para o Devoniano da Bacia do Rio do Peixe, Nordeste do Brasil
}

\author{
Proposal of new lithostratigraphic units for the Devonian \\ of the Rio do Peixe Basin, Northeast of Brazil
}

\author{
José Gedson Fernandes da Silva ${ }^{1 *}$, Valéria Centurion Córdoba ${ }^{2}$, \\ Luciano Henrique de Oliveira Caldas ${ }^{1}$
}

RESUMO: A análise estratigráfica de subsuperfície de estratos devonianos na Bacia do Rio do Peixe, recentemente identificados por palinologia, resultou na caracterização de duas novas formaçóes reunidas no Grupo Santa Helena. Estas unidades foram caracterizadas por meio de testemunhos, amostras laterais e de calha, perfis geofísicos convencionais de poço, perfil de imagem e sísmica 3D. A Formação Pilóes (unidade inferior), na qual predominam pelitos escuros e arenitos médios a muito finos, com brechas e conglomerados subordinados, e a Formaçáo Triunfo (unidade superior), composta por arenitos cinza-esbranquiçados, grossos a conglomeráticos, caulínicos, com estratificaçôes cruzadas, e conglomerados, com pelitos e arenitos finos intercalados. A Formação Pilōes é representada por fácies prodeltaicas-lacustres, com menor proporçáo de fácies de tálus, debritos e lobos turbidíticos arenosos, associadas a sistemas de leque deltaico e fluviodeltaico. A Formaçáo Triunfo é interpretada como depósitos fluviodeltaicos do tipo entrelaçado. O Grupo Santa Helena corresponde a uma tectonossequência depositada em um graben, com eixo deposicional NO-SE, durante um ciclo transgressivo-regressivo. Com a espessura de $343 \mathrm{~m}$ (isócora) no poço 1-PIL-1-PB (Pilóes n 1 ), esta sequência é limitada na base por uma não-conformidade e o limite superior é uma discordância angular, com um hiato de cerca de 265 milhôes de anos, separando-a da tectonossequência cretácea inferior (Grupo Rio do Peixe). Ignimbritos e brechas coignimbríticas (brecha vulcânica Poço da Jurema) foram reconhecidas na margem norte do Semigraben de Sousa. Há indícios de que o evento piroclástico e o preenchimento do graben eodevoniano tenham sido contemporâneos. Os resultados deste estudo indicam que a evoluçâo tectono-vulcano-sedimentar da bacia é poli-histórica. Esta atualização litoestratigráfica abre novas perspectivas para pesquisas geológicas na Bacia do Rio do Peixe, assim como em outras bacias interiores do Nordeste do Brasil.

PALAVRAS-CHAVE: Litoestratigrafia; Tectonossequência devoniana inferior; Formação Pilóes; Formação Triunfo; Grupo Santa Helena; Província Borborema.
ABSTRACT: Subsurface stratigraphic analysis of Devonian strata in the Rio do Peixe Basin, newly recognized by palynological studies, has resulted in the identification of two new formations assembled in the newly established Santa Helena Group. These units were characterized using cores, sidewall and cuttings samples, conventional well logs, image log and $3 D$ seismic data. The Pilöes Formation, the lower unit, is composed mainly of dark mudstones and medium-to-very fine-grained sandstones, with minor conglomerates and breccias, and the Triunfo Formation, the upper unit, comprises whitish grey, kaolinitic, coarsegrained to conglomeratic, cross stratified sandstones and conglomerates, with interbedded mudstones and fine-grained sandstones. The Piloes Formation is represented by prodeltaic lagoonal-lacustrine facies, with lesser associated subaqueous talus, debrite and sandy turbidite lobe facies, part of fandelta and delta systems. The Triunfo Formation is interpreted as braided fluviodeltaic facies. The Santa Helena Group corresponds to the Lower Devonian tectono-sequence deposited in a NW-SE-trending graben during a transgressive-regressive cycle. With $343 \mathrm{~m}$ of thickness (isochore) in well 1-PIL-1-PB (Piloes 1), this sequence has a non-conformity at the lower boundary and its upper boundary is an angular unconformity that represents a hiatus of about 265 Myr, at the base of the Lower Cretaceous tectono-sequence (Rio do Peixe Group). Ignimbrites and co-ignimbrite breccias (Poço da Jurema volcanic breccia) were recognized at the northern margin of the Sousa half-graben. There is evidence that the pyroclastic event is coeval with the Lower Devonian graben filling. The results of this study indicate a polyhistorical tectono-volcano-sedimentary evolution of the basin. This lithostratigraphic update brings new perspectives for geological research in the Rio do Peixe Basin, as well as in other inland basins of the Northeast of Brazil.

KEYWORDS: Lithostratigraphy, Early Devonian tectono-sequence, Pilóes Formation, Triunfo Formation, Santa Helena Group, Borborema Province.

${ }^{1}$ Unidade de Operações de Exploração e Produção do Rio Grande do Norte e Ceará, Petróleo Brasileiro S. A. - PETROBRAS, Natal (RN), Brasil. E-mails: gedson@ petrobras.com.br; lcaldas@petrobras.com.br

${ }^{2}$ Departamento de Geologia e Programa de Pós-Graduação em Geodinâmica e Geofísica da Universidade Federal do Rio Grande do Norte - UFRN, Natal (RN), Brasil. E-mail: valeria.geo@ufrnet.br

*Autor correspondente

Manuscrito ID: 30129. Recebido em: 01/07/2014. Aprovado em: 22/10/2014. 


\section{INTRODUÇÃO}

A revisão do arcabouço estratigráfico da Bacia do Rio do Peixe (BRP) foi motivada pela descoberta de rochas do Devoniano Inferior até então desconhecidas na bacia (Roesner et al. 2011). A atualização da coluna litoestratigráfica resultou da análise estratigráfica integrada de subsuperfície, apoiada na caracterização de fácies, sistemas e tratos deposicionais, sob a ótica da Estratigrafia de Sequências.

Quatro unidades litoestratigráficas são propostas para o Devoniano Inferior da BRP, três formais: a Formação Pilóes (inferior) e a Formação Triunfo (superior) — reunidas no Grupo Santa Helena - e a brecha vulcânica Poço da Jurema (informal).

Os resultados aqui apresentados abrem novas perspectivas para futuros estudos geológicos e uma melhor compreensão da evolução tectonossedimentar da bacia, além de contribuírem para ampliar o conhecimento sobre a Província Borborema e a paleogeografia do Gondwana ocidental, durante o Eodevoniano.

\section{CONTEXTO GEOLÓGICO}

A BRP está localizada em parte dos estados da Paraíba e do Ceará (Fig. 1). Faz parte do trend Cariri-Potiguar (Matos 1992), o qual abrange bacias de pequeno a médio porte, desde a Bacia Potiguar (BPT) até a Bacia do Araripe (BAP), inseridas na Província Borborema. A estrutura destas bacias rifte é caracterizada por grabens e altos internos originados em consequência do estiramento crustal que antecedeu à fragmentação do continente Gondwana nas placas africana e sulamericana, durante o Eocretáceo (Françolin \& Szatmari 1987, Sénant \& Popoff 1991, Ponte 1992, Françolin et al. 1994, Matos 1999).

$\mathrm{Na} \mathrm{BRP}$, estratos cretáceos preenchem quatro semigrabens assimétricos, denominados Icozinho (SgI), Brejo das FreirasTriunfo (SgBF-T), Sousa (SgS) e Pombal (SgP), separados por blocos aflorantes de granitóides brasilianos intrudidos em rochas metamórficas paleoproterozoicas (Medeiros et al. 2005). Estes semigrabens são delimitados por falhas NE, controladas pela Zona de Cisalhamento Portalegre (ZCPt) e, na porção sul, pela Falha de São Gonçalo (Malta), orientada aproximadamente E-O, paralela à Zona de Cisalhamento Patos $(\mathrm{ZCPa})$.

De acordo com Carvalho e Leonardi (1992), a montagem do atual arcabouço litoestratigráfico da BRP teve início com os trabalhos de Braun (1969), ao subdividir a Série Rio do Peixe (Moraes 1924) em três unidades informais (A, B e C), assim denominadas da base para o topo, equivalentes respectivamente às unidades informais $1,2 \mathrm{e}$ 3 de Ghignone et al. (1986).

As formaçóes Antenor Navarro e Sousa, propostas por Costa (1964), e Rio Piranhas, definida por Albuquerque (1970), foram reunidas no Grupo Rio do Peixe por Albuquerque (1970). A Formação Rio Piranhas foi renomeada Piranhas (Mabesoone 1972) e com as formaçôes Sousa e Antenor Navarro foram formalmente congregadas no Grupo Rio do Peixe (Mabesoone \& Campanha 1974).

Os estratos da BRP têm sido preferencialmente posicionados no Cretáceo Inferior (Moraes 1924, Braun 1969). Todavia, Mabesoone e Campanha (1974), por meio da análise de ostracodas, e Tinoco e Katoo (1975), ao estudarem os conchostráceos da Formação Sousa, atribuíram o início da sedimentação ao Neojurássico e o término da mesma durante o Eocretáceo.

Em estudo palinológico das amostras de testemunhos do poço estratigráfico Lagoa do Forno no 1 (2-LF-1-PB), perfurado no SgS, o Grupo Rio do Peixe foi primeiramente posicionado no Andar Aratu (Lima \& Coelho 1987) e depois reposicionado no Andar Rio da Serra (Regali 1990), podendo, no máximo, incluir a parte basal do Andar Aratu (Arai 2006).

Diversos estudos (Antunes et al. 2007, Costa P. et al. 2007, Córdoba et al. 2008, Antunes et al. 2009, Nunes da Silva 2009, Conde Blanco 2013) trouxeram novas perspectivas sobre a evolução tectonossedimentar da bacia, com ênfase em contatos interdigitados entre as três formaçóes.

Na margem flexural, depósitos fluviais entrelaçados (Lima Filho 1991) são interpretados por Scherer et al. (2007) como fácies proximais de um sistema fluvial distributário que passam lateralmente para depósitos de planície aluvial com lobos de extravasamento distais. Junto à margem falhada do Semigraben de Brejo das Freiras, Sousa et al. (2007) identificaram depósitos de leques aluviais da Formação Piranhas interdigitados com as outras unidades.

Roesner et al. (2011) identificaram uma associação palinológica diagnóstica da Zona Mórfon emsiensis de Rubinstein et al. (2005), datada como eolochkoviana-?eopraguiana, seguramente pré-neoemsiana (eodevoniana), até então desconhecida na bacia, em estratos sotopostos à tectonossequência cretácea inferior, amostrados em três poços perfurados pela Petróleo Brasileiro S.A. (PETROBRAS).

Os autores relatam a diminuição do conteúdo de elementos do microfitoplâncton de parede orgânica (MPO), em relação aos constituintes continentais (miósporos e fitoclastos), da porçáo basal para a superior da sucessão devoniana. Como os elementos do MPO têm afinidade marinha, este fato sugere mudança no ambiente deposicional de transicional para continental. 


\section{BASE DE DADOS E MÉTODOS}

A base de dados utilizada neste estudo é composta por três poços pioneiros e pelo volume sísmico 3D do Rio do Peixe provenientes das atividades de exploração petrolífera realizadas pela PETROBRAS no bloco exploratório BRPT-41, o qual está situado nos municípios de Santa Helena e São João do Rio do Peixe, na Paraíba (Fig. 1).

Os dados de poço são constituídos por testemunhos, amostras laterais e de calha, assim como dados digitais de perfis geofísicos convencionais (raios gama espectral, sônico, neutrão, densidade, resistividade, microrresistividade, caliper), além de perfil de imagem microrresistiva e de mergulho (dipmeter). O dado sísmico provém do levantamento sísmico 3D_Rio_do_Peixe, com 49,6 km² (Fig. 1).

A análise estratigráfica (Silva J. 2014) que fundamenta esta proposta utiliza a abordagem multidisciplinar, apoiada em técnicas de geologia sedimentar, tais como: interpretaçáo de padróes de curvas e rastreamento de feiçóes de perfis de poços, a caracterização de associaçóes de fácies e de seus padróes de empilhamento, identificação de superfícies estratigráficas, interpretação de elementos e sistemas deposicionais, de tratos de sistemas, além da sismoestratigrafia ajustada aos dados biocronoestratigráficos disponíveis.

\section{RESULTADOS}

\section{Correlação litológica}

A partir da relação entre a descrição das amostras de calha, laterais e de testemunhos com os padróes de perfis geofísicos dos poços, foi construída uma coluna litológica interpretada para cada poço (Fig. 2), subdividida em unidades litológicas descritivas (sensu Miall 1990), denominadas UL1 a UL8, as quais serviram de base para correlação litoestratigráfica entre os poços.

\section{Fácies e associações de fácies}

A caracterização de fácies levou em conta a descrição de quatro testemunhos, treze amostras laterais e de centenas de amostras de calha, em conjunto com os perfis geofísicos de poço. Dados de afloramentos também foram utilizados, especialmente no caso das fácies vulcanoclásticas.

Baseado em critérios litológicos, tamanho de grão e estruturas sedimentares, Silva J. (2014) caracteriza doze fácies principais na sucessão devoniana da BRP, descritas sucintamente na Tab. 1, em ordem decrescente do tamanho de grão.

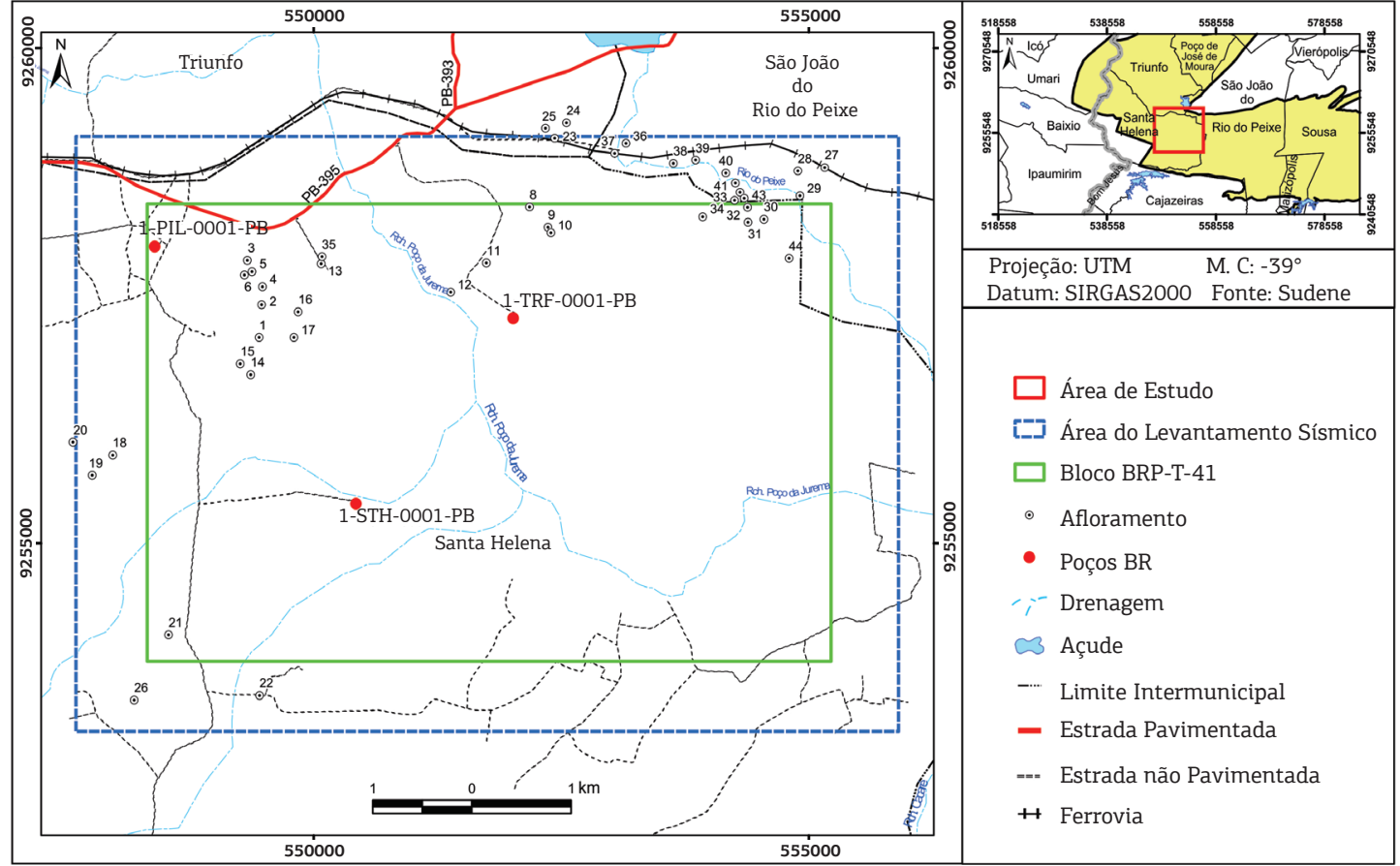

Fonte: Instituto Brasileiro de Geografia e Estatística e Petróleo Brasileiro S.A

Figura 1. Localização da Bacia do Rio do Peixe, com destaque para a área de estudo, com vias de acesso, poços perfurados pela Petróleo Brasileiro S.A. e principais afloramentos estudados. 
A

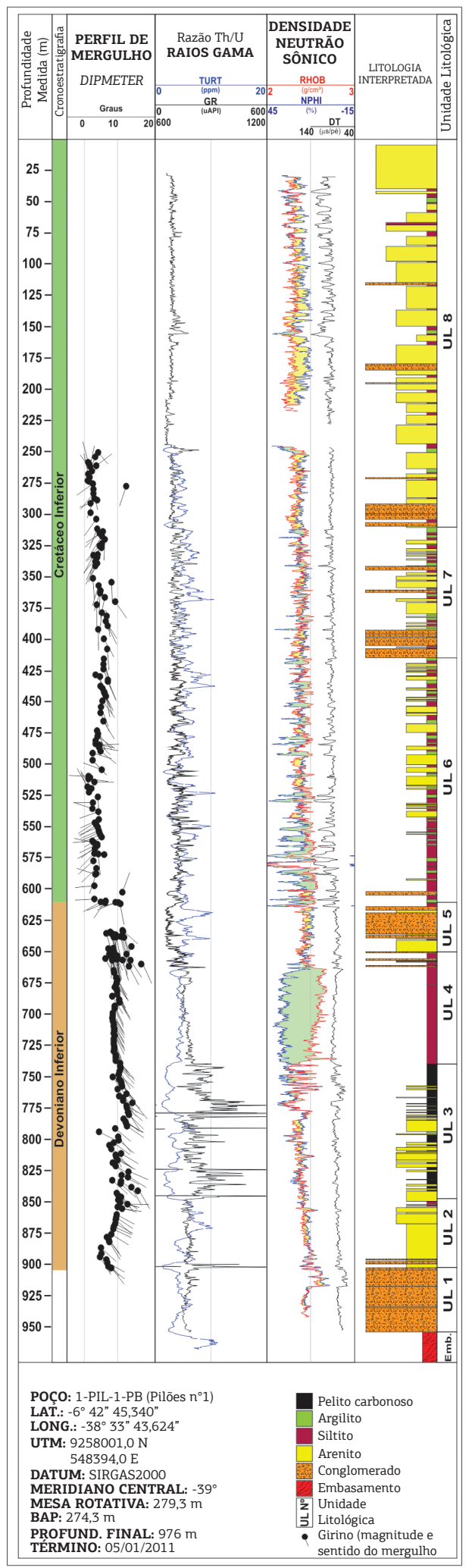

B

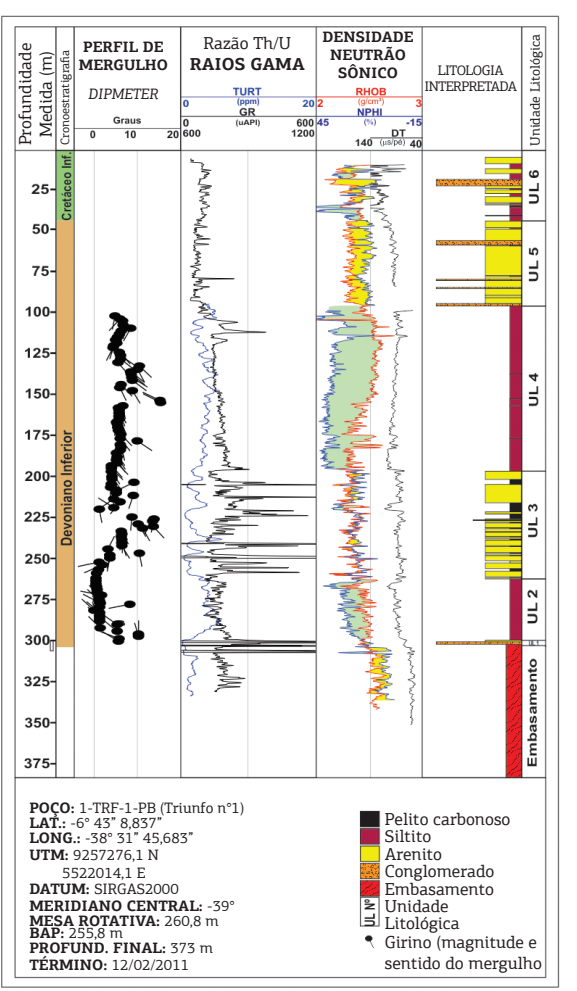

C

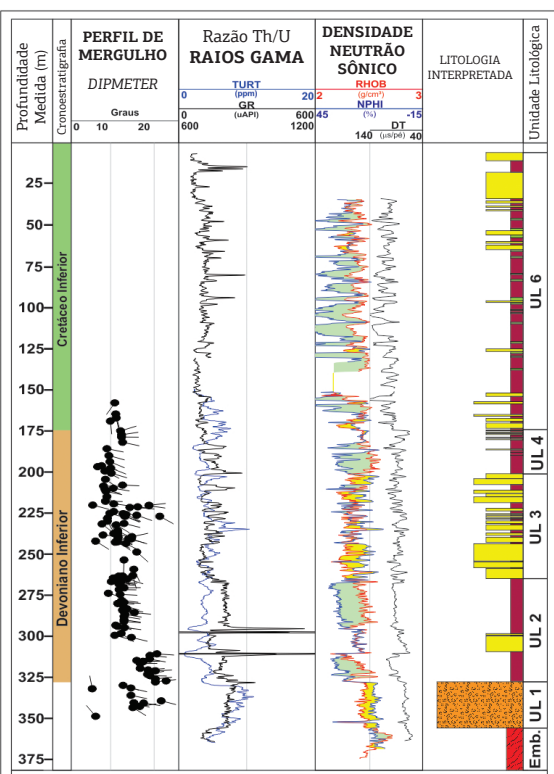

poço: 1-STH-1-PB (Santa Helena n ${ }^{\circ 1}$ )

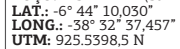

$550.422,9 \mathrm{E}$
DATUM: SIRGAS2000

MERIDIANO CENTRAL: -39

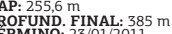

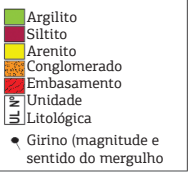

UTM: Universal Transversa de Mercator; DATUM: superfície ou modelo matemático de referência geodésica; SIRGAS: Sistema de Referência Geocêntrico para as Américas; BAP: boca ou base do antepoço, cota altimétrica.

Figura 2. Perfis litológicos integrados dos poços estudados: (A) 1-PIL-1-PB (Pilões $n^{\circ} 1$ ), (B) 1-TRF-1-PB (Triunfo $n^{\circ} 1$ ) e (C) 1-STH-1-PB (Santa Helena $\mathrm{n}^{\circ} 1$ ). 
Tabela 1. Fácies descritas na sucessão devoniana inferior.

\begin{tabular}{|c|c|c|}
\hline Fácies & Descrição & Interpretação \\
\hline $\mathrm{Bcm}$ & $\begin{array}{l}\text { Brechas clasto-suportadas, maciças, com seixos, calhaus e } \\
\text { blocos, matriz argilosa (clorítica), com vesículas. Em parte com } \\
\text { clastos sustentados pela matriz (Bmm) }\end{array}$ & \multirow{2}{*}{$\begin{array}{l}\text { Depósitos de correntes quentes densas e } \\
\text { concentradas resultantes do colapso de plumas } \\
\text { derivadas de explosões vulcânicas (fluxos } \\
\text { piroclásticos). }\end{array}$} \\
\hline Igb & $\begin{array}{l}\text { Ignimbritos, creme-claros, alaranjados, avermelhados, com } \\
\text { litoclastos do embasamento, fiammes e púmices. }\end{array}$ & \\
\hline Cbm & $\begin{array}{l}\text { Ortoconglomerados a blocos maciços, grão-sustentados, com } \\
\text { aspecto de brecha, sem estratificações visíveis. }\end{array}$ & $\begin{array}{l}\text { Depósito de queda de blocos e deslizamento, junto a } \\
\text { áreas com alto declive. }\end{array}$ \\
\hline $\mathrm{Cmm}$ & $\begin{array}{l}\text { Conglomerados matriz-sustentados maciços, com calhaus e } \\
\text { blocos arredondados a angulosos, em matriz lamosa ou de } \\
\text { arenito argiloso. }\end{array}$ & $\begin{array}{l}\text { Depósito de fluxos gravitacionais com matriz de } \\
\text { alta viscosidade que transportam cascalho e blocos } \\
\text { para as porções mais profundas da bacia. }\end{array}$ \\
\hline Csm & $\begin{array}{l}\text { Ortoconglomerados a seixos com raros calhaus e fragmentos } \\
\text { vulcânicos, sem estratificações visíveis. }\end{array}$ & $\begin{array}{l}\text { Depósitos de fluxos gravitacionais de sedimentos, } \\
\text { com alta concentração de sólidos, contendo } \\
\text { epiclastos e/ou depósitos piroclásticos. }\end{array}$ \\
\hline Ac & $\begin{array}{l}\text { Arenitos conglomeráticos, maciços, em parte com gradação } \\
\text { normal (Acn), inversa (Aci), sem estratificações visíveis. }\end{array}$ & $\begin{array}{l}\text { Fluxos gravitacionais de sedimentos (fluxos de } \\
\text { detritos), com deposição subaquosa, e turbiditos } \\
\text { concentrados. }\end{array}$ \\
\hline AG & $\begin{array}{l}\text { Arenitos grossos a muito grossos, também conglomeráticos } \\
\text { (AGc), arcóseos, cauliníticos, com raros intraclastos pelíticos, } \\
\text { com estratificações cruzadas. }\end{array}$ & $\begin{array}{l}\text { Fluxos trativos unidirecionais de alta energia, } \\
\text { gerando formas de leito 3D. As paleocorrentes têm } \\
\text { rumo preferencial para o quadrante NO. }\end{array}$ \\
\hline Agn & $\begin{array}{l}\text { Arenitos grossos a médios, também finos a muito finos com } \\
\text { gradação normal. Contato basal brusco, por vezes com marcas } \\
\text { de carga. }\end{array}$ & $\begin{array}{l}\text { Fluxos turbidíticos com deposição por fricção basal } \\
\text { e decantação. }\end{array}$ \\
\hline $\mathbf{A F}$ & $\begin{array}{l}\text { Arenitos finos a muito finos, maciços, com estratificação } \\
\text { plano-paralela ou de baixo ângulo (AFe). No topo, laminação } \\
\text { cruzada por corrente/onda (AFl) ou intraclastos (AFi). Contato } \\
\text { basal brusco, gradacional ou brusco no topo. }\end{array}$ & $\begin{array}{l}\text { Fluxos turbidíticos diluídos com deposição por } \\
\text { tração, em regime de fluxo superior, e com pouca } \\
\text { decantação. }\end{array}$ \\
\hline Iap & $\begin{array}{l}\text { Arenitos médios a muito finos e siltitos/argilitos } \\
\text { subordinados, em parte carbonosos, com analcima. } \\
\text { Laminações incipientes a plano-paralelas, por vezes, exibem } \\
\text { gradação normal e laminações cruzadas por corrente. }\end{array}$ & $\begin{array}{l}\text { Fluxos turbidíticos diluidos depositados por } \\
\text { decantação e tração associados a lâminas } \\
\text { carbonosas e depósitos vulcânicos cineríticos } \\
\text { alterados (analcima/clorita). }\end{array}$ \\
\hline Ipa & $\begin{array}{l}\text { Siltitos/argilitos com níveis carbonosos, com analcima, e } \\
\text { arenitos finos a muito finos, em parte argilosos (cloríticos) e } \\
\text { micáceos, subordinados. Por vezes ocorrem marcas de carga e } \\
\text { erosão, estrutura em chama e pseudonódulos. }\end{array}$ & $\begin{array}{l}\text { Fluxos turbidíticos diluídos depositados por } \\
\text { decantação e tração, associados a lâminas } \\
\text { carbonosas e depósitos vulcânicos cineríticos } \\
\text { alterados (analcima/clorita). }\end{array}$ \\
\hline $\mathbf{P}$ & $\begin{array}{l}\text { Pelitos (siltitos/argilitos) cinza-escuros, pretos maciços } \\
\text { (Pm), com laminação (Pl) e com gradação normal (Pn), } \\
\text { subordinadamente castanho-escuros, em parte avermelhados, } \\
\text { micáceos, também carbonosos e betuminosos (Pc). }\end{array}$ & $\begin{array}{l}\text { Pelitos depositados por decantação e tração em } \\
\text { correntes de fundo. A porção mais argilosa e } \\
\text { carbonosa é formada pela decantação de plumas } \\
\text { hipopicnais segregadas (lofting), contribuição } \\
\text { pelágica e vulcânica. }\end{array}$ \\
\hline
\end{tabular}

Fonte: Silva J. (2014).

Estas doze fácies foram agrupadas em sete associaçôes de fácies, relacionadas a elementos deposicionais, sumariadas na Tab. 2. A descrição detalhada das fácies e das associações de fácies consta da dissertação inédita do primeiro autor (Silva J. 2014).

\section{Padrões de empilhamento de fácies, superfícies-chave e unidades genéticas}

O poço 1-PIL-1-PB (Pilóes no 1 ) foi escolhido como padrão, pois tem a sucessão sedimentar mais completa entre os três poços perfurados pela PETROBRAS (Fig. 2). $\mathrm{Na}$ Fig. 3, considerando-se a baixa frequência, podemos observar que o empilhamento é retrogradacional a partir da base da sucessão devoniana, com depósitos de tálus subaquoso (TS) seguidos de lobos areníticos subaquosos proximais e intermediários (LSP, LSI), os quais dáo lugar a lobos areníticos subaquosos distais (LSD) e pelitos de fundo de bacia, carbonosos e muito radioativos. No topo destes, se posiciona uma superfície de inundação máxima (SIM), a partir da qual o padrão de empilhamento torna-se 
Tabela 2. Associação de fácies interpretadas para a sucessão devoniana da Bacia do Rio do Peixe.

\begin{tabular}{|c|c|c|}
\hline $\begin{array}{l}\text { Associação } \\
\text { de Fácies }\end{array}$ & Descrição & Interpretação \\
\hline $\begin{array}{l}\text { DV } \\
\text { Depósitos } \\
\text { vulcanoclásticos }\end{array}$ & $\begin{array}{l}\text { Brechas clasto e matriz suportadas (Bcm e Bmm) } \\
\text { associadas a ignimbritos (Igb). }\end{array}$ & $\begin{array}{l}\text { Depósitos de fluxos piroclásticos subaéreos e } \\
\text { subaquosos (?). A fácies Bcm ocorre na região mais } \\
\text { proximal do cone de ejeção. Bmm e Igb ocorrem mais } \\
\text { afastadas. }\end{array}$ \\
\hline $\begin{array}{l}\text { TS } \\
\text { Tálus subaquoso }\end{array}$ & $\begin{array}{l}\text { Ortoconglomerados }(\mathrm{Cbm} \text { e } \mathrm{Csm}) \text {, em parte com } \\
\text { matriz argilosa }(\mathrm{Cmm}) \text {. Por vezes interdigitados } \\
\text { com fácies interestratificadas (Iap, Ipa). }\end{array}$ & $\begin{array}{l}\text { Tálus subaquoso depositado por fluxo de grãos ou } \\
\text { queda de fragmentos do embasamento junto a uma } \\
\text { escarpa, intercalados com depósitos de fundo de bacia. }\end{array}$ \\
\hline $\begin{array}{l}\text { LSP } \\
\text { Lobos subaquosos } \\
\text { proximais }\end{array}$ & $\begin{array}{l}\text { Conglomerados (Csm), maciços, com seixos e } \\
\text { raros calhaus, e arenitos conglomeráticos, sem } \\
\text { estruturas sedimentares visíveis }(\mathrm{Ac}) \text { ou com } \\
\text { gradação normal ou inversa (Acn/Aci). }\end{array}$ & $\begin{array}{l}\text { Lobos subaquosos proximais depositados por fluxos de } \\
\text { detritos com matriz arenosa e em parte lamosa, além } \\
\text { de turbiditos proximais cascalhosos a arenosos. }\end{array}$ \\
\hline $\begin{array}{l}\text { LSI } \\
\text { Lobos subaquosos } \\
\text { intermediários }\end{array}$ & $\begin{array}{l}\text { Interestratificados arenopelíticos (Iap) } \\
\text { intercalados com arenitos finos a muito finos } \\
\text { (AF) e grossos a médios (Agn), com acamamento } \\
\text { espesso. Subordinadamente as fácies Ipa e P } \\
\text { ocorrem intercaladas. }\end{array}$ & $\begin{array}{l}\text { Lobos subaquosos intermediários depositados por } \\
\text { fluxos gravitacionais de sedimentos nas porções mais } \\
\text { afastadas de leques deltaicos ou de deltas do tipo } \\
\text { entrelaçado (braided deltas). }\end{array}$ \\
\hline $\begin{array}{l}\text { LSD } \\
\text { Lobos subaquosos } \\
\text { distais }\end{array}$ & $\begin{array}{l}\text { Predomina a litofácies Ipa com arenitos muito } \\
\text { finos, finos a médios (AF) e acamamento delgado. } \\
\text { Subordinamente, as litofácies Iap e P ocorrem } \\
\text { intercaladas. }\end{array}$ & $\begin{array}{l}\text { Lobos subaquosos distais depositados por fluxos } \\
\text { gravitacionais diluídos e decantação na transição } \\
\text { entre a região principal de deposição dos lobos e dos } \\
\text { depósitos de fundo de bacia. }\end{array}$ \\
\hline $\begin{array}{l}\text { PRD } \\
\text { Depósitos de } \\
\text { prodelta/proleque }\end{array}$ & $\begin{array}{l}\text { Predomina a litofácies } \mathrm{P} \text {, laminada (Pl), em parte } \\
\text { maciça (Pm) ou gradada (Pn), carbonosa (Pc). } \\
\text { Subordinadamente ocorre a Ipa. }\end{array}$ & $\begin{array}{l}\text { Depósitos distais de deltas do tipo entrelaçado ou de leques } \\
\text { deltaicos na zona de transição para o fundo da bacia. }\end{array}$ \\
\hline $\begin{array}{l}\text { BFD } \\
\text { Barras } \\
\text { fluviodeltaicas } \\
\text { (braided delta) }\end{array}$ & $\begin{array}{l}\text { Arenitos grossos e conglomeráticos com } \\
\text { estratificação cruzada ( } \mathrm{AG}, \mathrm{AGc}) \text { e conglomerados } \\
\text { seixosos maciços (Csm), com arenitos e pelitos } \\
\text { intercalados. }\end{array}$ & $\begin{array}{l}\text { Barras depositadas por fluxos trativos de um sistema } \\
\text { fluviodeltaico entrelaçado (braided), com paleocorrentes } \\
\text { para o quadrante NO. }\end{array}$ \\
\hline
\end{tabular}

Fonte: Silva J. (2014).

agradacional a progradacional, com pelitos prodeltaicos (PRD) que passam a arenitos grossos, em parte conglomeráticos, de origem fluviodeltaica (BFD), limitados por uma discordância angular (DS) no topo.

De acordo com a arquitetura estratigráfica proposta, a sucessão devoniana é interpretada como uma sequência transgressivo-regressiva sensu Johnson e Murphy (1984). Por outro lado, levando-se em conta a importância da tectônica na acomodação e preservação desta sucessão sedimentar, é denominada tectonossequência devoniana inferior, em consonância com a tectonossequência cretácea inferior (Grupo Rio do Peixe). Este arcabouço estratigráfico genético está sumariado na Fig. 3.

Considerando-se os padrôes de empilhamento das fácies e as superfícies estratigráficas-chave marcadas nos poços, interpreta-se na seção sísmica (Fig. 4): o refletor Rf1 como uma não-conformidade, que coincide com a superfície transgressiva (ST), na base dos depósitos de tálus ou lobos subaquosos proximais. O Rf2 representa a SIM, no topo do intervalo pelítico radioativo, e o refletor Rf3 está associado à discordância subaérea (DS), localmente angular (1-PIL-1-PB), no topo da tectonossequência devoniana inferior.

\section{PROPOSTA DE NOVAS UNIDADES LITOESTRATIGRÁFICAS}

Os estratos devonianos têm identidade litológica, gênese e história geológica própria, limites definidos e rastreáveis em subsuperfície, por meio de perfis geofísicos de poço e de sísmica de reflexão. Também atendem aos critérios de uniformidade litológica, continuidade e mapeabilidade, conforme preconizado nos códigos e guias estratigráficos (Petri et al. 1986a, 1986b, North American Commission on Stratigraphic Nomenclature 2005).

As características litológicas e genéticas das unidades devonianas são diferentes das demais unidades litoestratigráficas da BRP, assim como das unidades potencialmente cronocorrelatas nas bacias do Parnaíba (BPB), Araripe (BAP) e Jatobá (BJB), além de estarem ausentes do Léxico Estratigráfico do Brasil (Baptista et al. 1984) e 


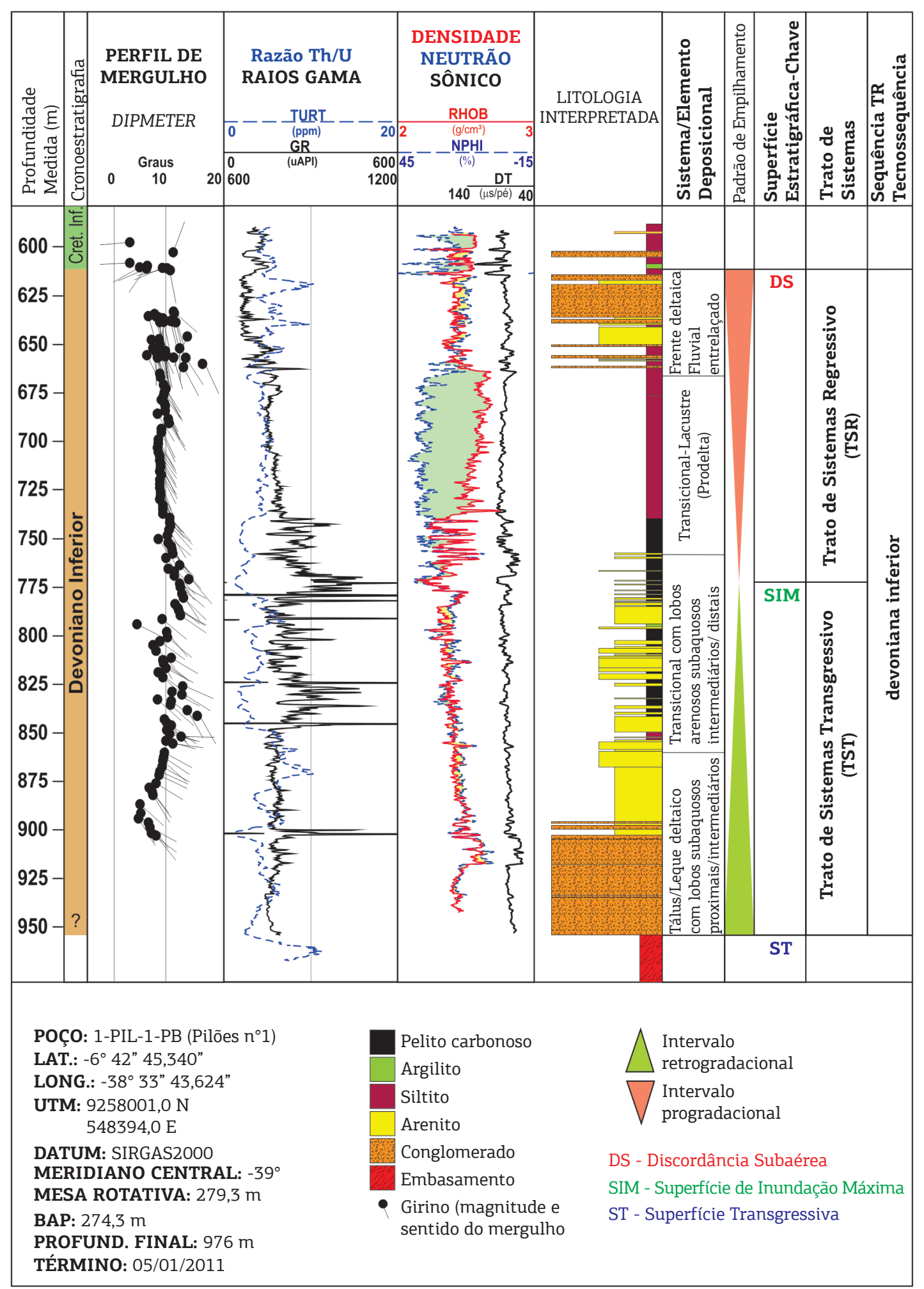

UTM: Universal Transversa de Mercator; DATUM: superfície ou modelo matemático de referência geodésica; SIRGAS: Sistema de Referência Geocêntrico para as Américas; BAP: boca ou base do antepoço, cota altimétrica.

Figura 3. Padrões de empilhamento e arcabouço estratigráfico genético do Devoniano Inferior. 


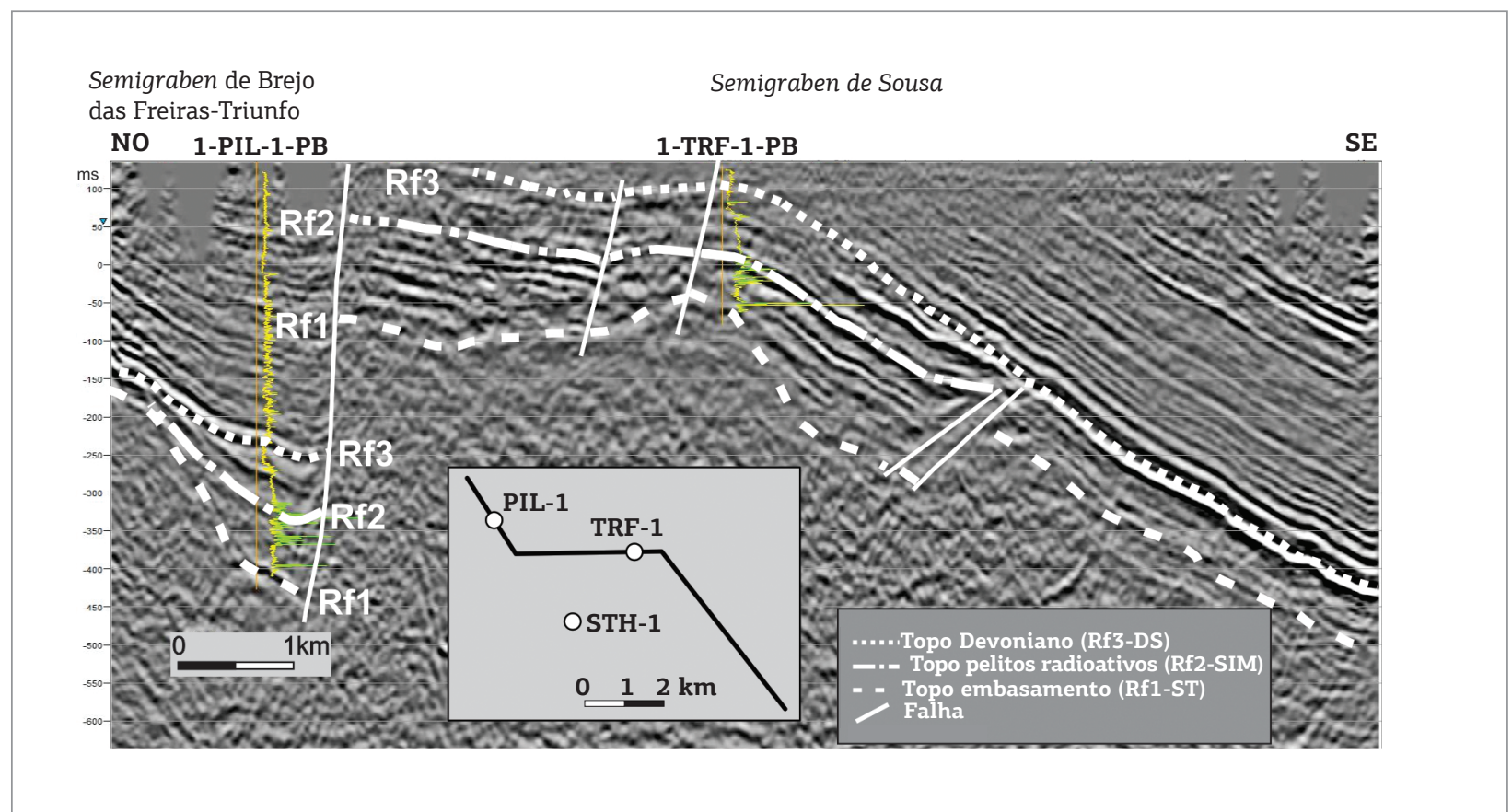

Figura 4. Seção sísmica arbitrária (em tempo) passando pelos poços PIL-1 e TRF-1 e pelo Alto de Santa Helena, com destaque para a falha de Brejo das Freiras (Portalegre), limite entre o SgS e o SgBF-T, próxima ao poço 1-PIL-1-PB.

sem quaisquer referências em publicações geocientíficas nacionais e internacionais.

\section{Formação Pilões}

\section{Justificativa}

As características litofaciológicas, o contexto deposicional e os padróes de perfis geofísicos de poço da unidade proposta são distintos das unidades litoestratigráficas adjacentes ou potencialmente cronocorrelatas nas bacias do Parnaíba, Araripe e Jatobá.

\section{Hierarquia}

É proposta como Formação pois a unidade possui continuidade lateral e vertical suficiente para ser mapeada em subsuperfície e em superfície, na escala de 1:25.000.

\section{Nome}

A denominação Pilōes é inédita e alude ao poço 1-PIL-1-PB (Pilóes no 1 ), no qual a unidade tem a seção-tipo descrita. O termo geográfico refere-se ao açude Pilóes, localizado entre os municípios de Triunfo e São João do Rio do Peixe, na Paraíba (Fig. 1).

\section{Poço-tipo}

A unidade tem a seção-tipo descrita no poço 1-PIL-1-PB (Fig. 5), cujas coordenadas geográficas são: 6 42’ 45,340" $S$ de latitude e $38^{\circ} 33^{\prime} 43,624^{\prime \prime}$ O de longitude, situado na localidade de Melancia, Município de Santa Helena, na Paraíba (Fig. 1). A cota altimétrica é 274,3 m.

\section{Repositório de amostras}

As amostras de rochas (testemunhos, amostras laterais e de calha) da Formação Pilóes estão depositadas na Gerência de Sedimentologia e Estratigrafia, da Gerência de Exploração da Unidade Operacional do Rio Grande do Norte e Ceará, PETROBRAS, localizada na Rua Euzébio Rocha, no 1000, Cidade da Esperança, Natal, Rio Grande do Norte.

\section{Descrição}

Esta unidade é composta predominantemente por siltitos e argilitos, cinza-escuros a claros, também castanho-avermelhados (oxidados), em parte verde-claros, laminados ou maciços, localmente com grãos de quartzo e fragmentos de rocha dispersos, com intervalos carbonosos betuminosos, muito radioativos, com grumos e níveis ricos em analcima e concreçôes de calcita.

Arenitos cinza-claro/esverdeados, acastanhados a alaranjados, de granulação fina a grossa, quartzosos, feldspáticos, micáceos (biotita e muscovita), com intraclastos pelíticos, seleção moderada a pobre, maciços ou com gradação normal, estratificação plano-paralela e cruzada de baixo ângulo e topo ondulado ou com laminação cruzada por corrente. Estes arenitos ocorrem em camadas isoladas ou em ciclos (ritmitos) compostos por camadas centimétricas a métricas. 


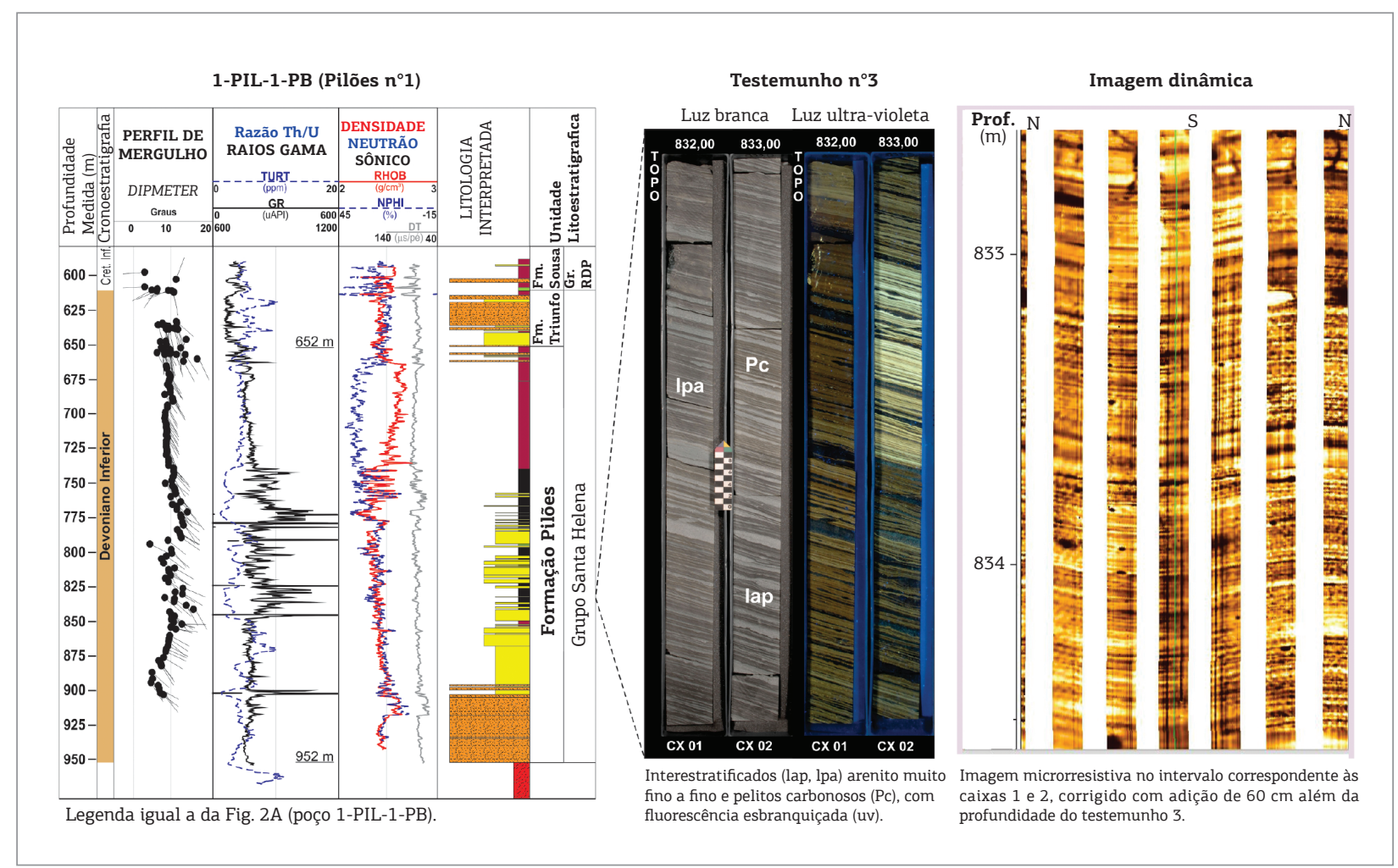

Figura 5. Perfil-tipo da Formação Pilões no poço 1-PIL-1-PB, com destaque para as fácies interestratificadas, com arenitos finos a muito finos e pelitos carbonosos (Iap, Ipa e Pc).

Na porção superior, predominam siltitos cinza-escuros a claros, maciços ou com laminaçôes plano-paralelas, com anomalia nos perfis densidade e neutrão, provavelmente devido à influência vulcânica (cloritização).

Localmente, na base da unidade, ocorrem conglomerados seixosos e arenitos conglomeráticos, sotopostos a ortoconglomerado, com aspecto de brecha sedimentar, composto por seixos, calhaus e blocos subarredondados a angulosos e, em parte muito cimentados, com as fácies pelíticas e areníticas intercaladas.

Em superfície, ocorre como folhelhos rijos/médios (semiduros) a moles, castanho-avermelhados, roxos a amarelo-mostarda, e arenitos muito finos, maciços, micáceos, com gradação normal para siltitos. Subordinadamente, arenitos finos a muito finos, maciços a laminados, localmente com microlaminaçóes clinoascendentes e estruturas convolutas, em camadas decimétricas, passando para o topo a arenitos conglomeráticos com seixos e grânulos angulosos, em corpos tabulares, com topo e base planos, com espessura centimétrica a decimétrica, contínuas lateralmente por dezenas de metros.

\section{Limites, espessura e área de ocorrência}

No poço-tipo (Fig. 5) a unidade tem $300 \mathrm{~m}$ de espessura (isócora) e o limite superior é transicional, marcado a
652,0 m (-372,7 $\mathrm{m})$ de profundidade medida, no topo do pacote pelítico estratigraficamente mais elevado. O limite inferior está a 952,0 m (-672,7 m), ao nível da superfície de não-conformidade. $\mathrm{Na}$ área do bloco BRP-T-41, a unidade está encaixada num baixo estrutural de direção NO-SE, sobre o Alto de Santa Helena, adelgaçando para nordeste, sudoeste e sudeste, por efeito de falhas e erosão.

\section{Correlação bioestratigráfica e idade}

Com abundantes palinomorfos e estéril em ostracodas, de acordo com Roesner et al. (2011) esta unidade possui uma associação palinológica diagnóstica do Eodevoniano, correlacionada à porção superior da Formação Jaicós, do Grupo Serra Grande, e à parte inferior da Formaçáo Itaim, do Grupo Canindé, da Bacia do Parnaíba (Vaz et al. 2007).

$\mathrm{Na}$ Bacia do Amazonas correlaciona-se às formaçôes Manacapuru e Jatapu, do Grupo Trombetas (Cunha et al. 2007), e na Bacia do Paraná à Formação Furnas e à porção inferior do Membro Jaguariaíva da Formação Ponta Grossa, na base do Grupo Paraná (Milani et al. 2007).

\section{Gênese e contexto paleogeográfico}

Nesta unidade, predominam pelitos e psamitos interacamadados depositados por fluxos gravitacionais de 
sedimentos (associaçóes de fácies LSP, LSD e LSI) interpretados como lobos subaquosos provenientes de leques deltaicos e de deltas do tipo entrelaçado (associação de fácies BFD), e que passam a fácies pelíticas de prodelta (associação de fácies PRD), no topo. Na porção basal, podem estar presentes depósitos psefíticos de tálus subaquoso (associação de fácies TS) e intercalaçóes de vulcanoclásticas (associação de fácies DV).

As interpretações, com base na análise sismoestratigráfica, na arquitetura dos sistemas/elementos deposicionais e nos dados palinológicos (Roesner et al. 2011) e micropetrográficos (Silva I. 2014) sugerem uma mudança no ambiente deposicional de transicional (água salobra) para continental (água doce).

\section{Observaçōes}

Esta unidade está bem representada no poço 1-TRF-1-PB e está parcialmente erodida no poço 1-STH-1-PB.

\section{Formação Triunfo}

\section{Justificativa}

Os padrōes de perfis geofísicos de poço, as características petrográficas, litológicas e faciológicas, o ambiente deposicional e o contexto tectônico são distintos das unidades litoestratigráficas adjacentes ou potencialmente cronocorrelatas nas bacias do Parnaíba (formações Jaicós e Itaim), Araripe (Formação Cariri) e Jatobá (Formação Tacaratu).

\section{Hierarquia}

É proposta como Formação, pois possui persistência lateral e vertical para ser mapeada, na escala de 1:25.000, em subsuperfície e em superfície. Aflora em outros pontos da margem flexural do $\mathrm{SgS}$, fora dos limites da área estudada.

\section{Nome}

A denominação Triunfo refere-se ao poço 1-TRF-1-PB (Triunfo $n^{\circ} 1$ ) no qual a unidade tem a seção-tipo. O termo geográfico faz referência ao município homônimo, no Estado da Paraíba.

Topônimo semelhante já havia sido utilizado por Galeão da Silva et al. (1974) para uma unidade clástica pré-cambriana da Bacia do Amazonas. Porém, a designação original "Formação Prosperança” sensu Caputo et al. (1972) tem sido utilizada formalmente nas cartas estratigráficas das bacias do Amazonas (Cunha et al. 2007) e Solimóes (Wanderley Filho et al. 2007).

Schneider et al. (1974) denominaram como "Membro Triunfo" o primeiro dos três intervalos estratigráficos da
Formação Rio Bonito, Permiano da Bacia do Paraná, tomando como referência o município de São João do Triunfo (PR), onde está situada a seção-tipo da unidade. Portanto não há motivo para confusão em termos de posição geográfica, de litocronoestratigrafia ou de hierarquia entre a unidade da Bacia do Paraná e esta aqui proposta para a Bacia do Rio do Peixe.

\section{Poço-tipo}

A unidade tem a seção-tipo descrita no poço 1-TRF-1-PB (Fig. 6), cujas coordenadas geográficas são: 6 43' 8,837” S de latitude e $38^{\circ} 31^{\prime} 45,683$ " O de longitude, situado no Município de Santa Helena, Paraíba (Fig. 1). A cota altimétrica é $255,8 \mathrm{~m}$.

\section{REPOSITÓRIO DAS AMOSTRAS DE ROCHA}

As amostras de calha representativas da Formação Triunfo estão depositadas na Gerência de Sedimentologia e Estratigrafia, da Gerência de Exploração da Unidade Operacional do Rio Grande do Norte e Ceará, localizada na Rua Euzébio Rocha, no 1000, Cidade da Esperança, Natal, Rio Grande do Norte.

\section{Descrição}

É composta principalmente por arenitos cinza-esbranquiçados ou hialinos, localmente avermelhados, grossos a conglomeráticos, mal selecionados, com grãos subangulares a subarredondados, quartzosos, feldspáticos, caulínicos, com arenitos finos a médios subordinados. São calcíferos, friáveis a desagregados, com boa porosidade aparente, contendo estratificaçóes cruzadas visíveis na imagem microrresistiva, e raros siltitos e argilitos cinza-escuros, verde-claros e castanho-avermelhados/escuros, micáceos, moles e hidratáveis intercalados.

Em superfície, é comum uma crosta avermelhada devido ao intemperismo e precipitação de óxido de ferro, porém a rocha fresca geralmente é cinza-esbranquiçada. As melhores exposiçóes, em corte, estão nas terras da Fazenda Areias, a sudoeste da casa-sede, no término de uma estrada carroçável que dá acesso à base de uma locação não perfurada pela PETROBRAS (Afloramento 13 - latitude 6 42' 55.00” S e longitude $38^{\circ} 32^{\prime} 46,67^{\prime \prime} \mathrm{O}$ ).

No afloramento 13 , o empilhamento perfaz cerca de quatro metros $(4 \mathrm{~m})$, composto por ciclos decimétricos a métricos, com granodecrescência ascendente, os quais iniciam com conglomerados e/ou arenitos conglomeráticos, com seixos angulosos a subangulosos, predominantemente de quartzo, passando a arenitos muito grossos a grossos, localmente médios, caulínicos, com camadas pelíticas arroxeadas na porção superior da sucessão vertical. Predominam estratificações cruzadas acanaladas de médio porte e tangenciais, com sentido preferencial de 


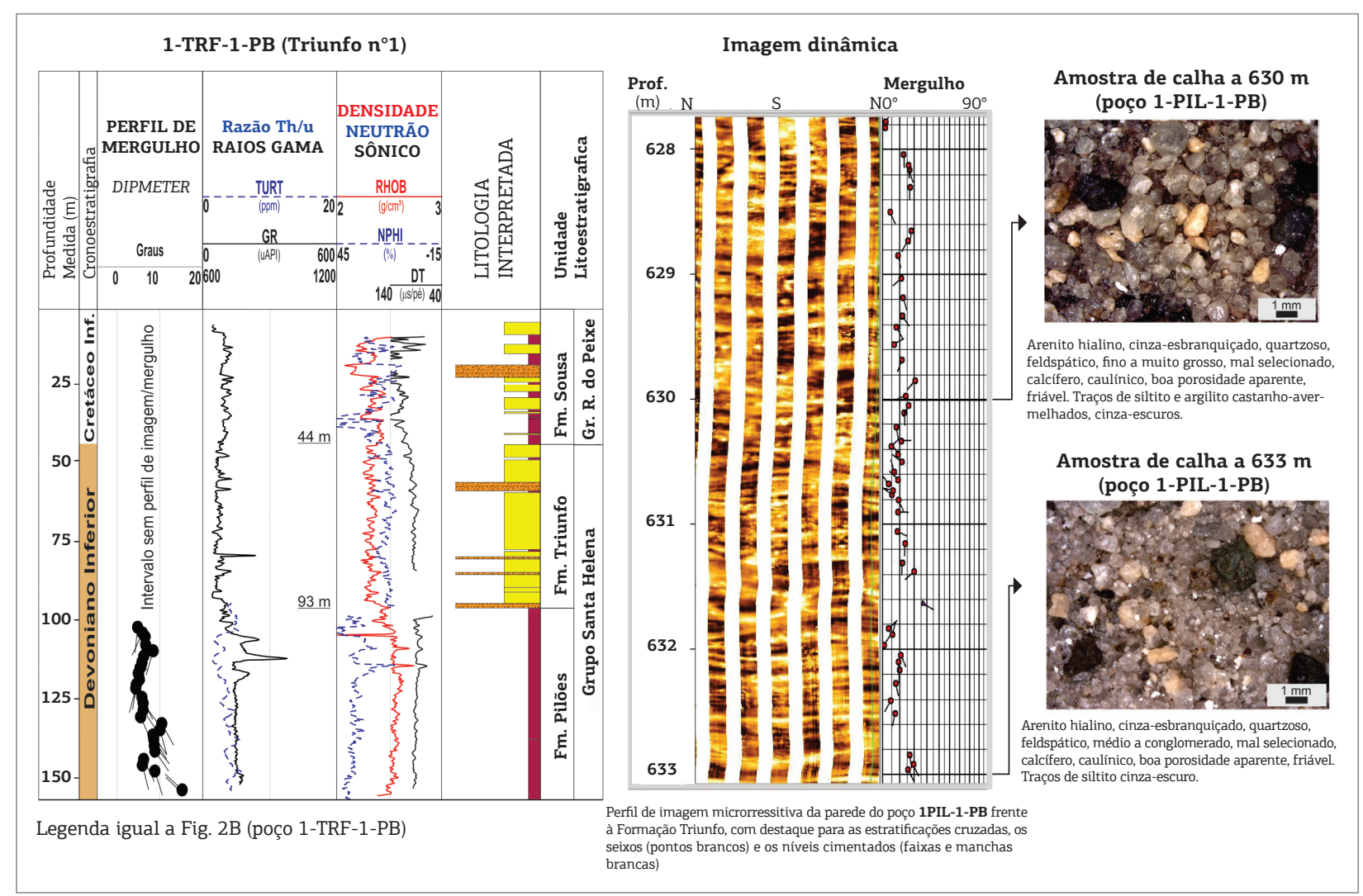

Figura 6. Perfil-tipo da Formação Triunfo no poço 1-TRF-1-PB, com destaque para a imagem microrresistiva dos arenitos grossos conglomeráticos estratificados (AG) e seu aspecto em amostra de calha, no poço 1-PIL-1-PB.

paleocorrentes para ONO $\left(270^{\circ}-290^{\circ}\right)$, medidas de forma expedita em dois pontos do afloramento, portanto sem representação estatística.

\section{Limites, espessura e ocorrência}

No poço-tipo (Fig. 6), a unidade tem $49 \mathrm{~m}$ de espessura (isócora), com o limite superior discordante, posicionado a 44,0 m (216,8 m), e o inferior a 93,0 m (167,8 m), de profundidade medida, marcado na base do pacote expressivo de arenito, estratigraficamente mais inferior, em contato abrupto-conforme com a Formaçáo Pilóes.

Está presente no poço 1-PIL-1-PB, com $43 \mathrm{~m}$ de espessura, em contato basal gradacional-interdigitado, com a Formação Pilóes, e limitada no topo por uma discordância angular com a Formação Sousa. Está ausente no poço 1-STH-1-PB.

\section{Correlação bioestratigráfica e idade}

Esta unidade é estéril em ostracodas. Devido à natureza essencialmente arenoconglomerática, contém poucos palinomorfos indicativos de idade eodevoniana. É posicionada no Devoniano Inferior, devido à evidência de discordância angular no seu topo, a composição arcoseana e a concordância da atitude do seu acamamento e do rumo de paleocorrentes, com a unidade sotoposta (Formação Pilóes), com a qual mostra contato gradacional-interdigitado, no poço 1-PIL-1-PB.

\section{Gênese e contexto paleogeográfico}

Esta unidade arenoconglomerática foi depositada em uma fase de assoreamento da bacia eodevoniana, dominada por um sistema deposicional interpretado como fluviodeltaico entrelaçado (fuvial-braided delta) representado pela associação de fácies BFD.

Em termos paleogeográficos, a unidade representa um ambiente deposicional continental a montante dos ambientes parálico e marinho plataformal, característicos das formaçóes Jaicós (parte mais superior) e Itaim (parte mais inferior) na Bacia do Parnaíba (Vaz et al. 2007)

\section{Observaçôes}

No poço 1-PIL-1-PB, o acamamento mergulha entre $10^{\circ}$ e $15^{\circ}$ para S-SE, em discordância angular, a $609 \mathrm{~m}$ de profundidade, com a base da Formaçáo Sousa.

$\mathrm{Na}$ localidade de Sítio Tanque (latitude 6 $6^{\circ} 41^{\prime} 00,2$ " $S$ e longitude $38^{\circ} 21^{\prime} 06,9$ " O), a $20 \mathrm{Km}$ a ENE do poço 1-TRF-1-PB, a unidade assenta-se sobre o embasamento e tem paleocorrentes com rumo para ONO. 


\section{Grupo Santa Helena}

\section{Justificativa}

As formações Pilóes e Triunfo estão geneticamente relacionadas e constituem o registro de subsidência mecânica eodevoniana durante a evoluçáo tectonossedimentar da bacia. Estáo separadas do Grupo Rio do Peixe por uma discordância com um hiato de cerca de 265 milhóes de anos. Portanto, é factível agrupá-las numa unidade litoestratigráfica do mesmo nível hierárquico da unidade cretácea.

\section{Nome}

O nome Santa Helena faz referência ao município homônimo, no qual foi perfurado o poço 1-STH-1-PB (Santa Helena ${ }^{\circ} 1$ ), no Estado da Paraíba (Fig. 1). De acordo com o Léxico Estratigráfico do Brasil (Baptista et al. 1984), este termo foi utilizado por Miranda e Silva (1978) para uma das formaçóes do Grupo Bambuí. Contudo, não consta na carta estratigráfica da Bacia do São Francisco (Zalán \& Silva 2007), na qual figura a "Formação Serra de Santa Helena", proposta originalmente com Membro da Formação Paraopeba por Costa e Branco (1961).

A erosão da seção devoniana sobre as ombreiras do graben, e sobre a rampa do embasamento (SE), levou à maior preservação dos estratos do Grupo Santa Helena no quadrante $\mathrm{NO}$ da área, onde estão localizados os primeiros degraus profundos do Alto de Santa Helena. A unidade tem a seção mais completa, $343 \mathrm{~m}$ de espessura (isócora), amostrada no poço 1-PIL-1-PB (Pilóes no 1 ), indicada na Fig. 5.

A identificação de palinomorfos devonianos no poço 2-LF-1-PB (Lima \& Coelho 1987), no SgS, e na Bacia de Icó (Lima 1990), além de litotipos semelhantes na localidade de Sítio Tanque e em outras bacias interiores, sugerem que a unidade tenha ocorrência mais ampla.

\section{brecha vulcânica Poço da Jurema}

\section{Justificativa}

São rochas vulcanoclásticas, caracterizadas nesta pesquisa, cuja descrição litológica possibilita a identificação da mesma em outras áreas da BRP e da regiáo.

\section{Hierarquia}

É proposta como unidade informal, pois representa um registro vulcânico investigado apenas petrograficamente, cuja área de ocorrência pode não estar plenamente delimitada. Estudos faciológicos e litogeoquímicos, além de datação geocronológica, são necessários para melhor caracterização e formalização.

\section{Nome}

O termo litológico faz referência ao litotipo predominante e o termo geográfico refere-se ao Riacho Poço da Jurema, localizado próximo à área de afloramento da unidade.

\section{Área de exposição}

Aflora em uma frente de lavra e nas circunvizinhanças (Afloramento 25: latitude 6 $0^{\circ} 42$ '7.59” S e longitude $38^{\circ} 31^{\prime} 35.12^{\prime \prime} \mathrm{O}$ ), às margens da linha férrea ao sul do açude Pilóes, entre os municípios de Triunfo e São João do Rio do Peixe, no Estado da Paraíba (Fig. 1).

\section{Descrição}

É composta por brechas vulcânicas, com fragmentos angulosos a subangulosos de rochas do embasamento (xistos, milonitos e granitóides) em matriz fina, geralmente cloritizada, localmente com feiçóes de escape de gases (vesículas milimétricas a submilimétricas), acamamento incipiente a pobremente definido. Localmente, há ignimbritos creme-alaranjados, com material juvenil (púmice) e estruturas típicas de fiammes, além de litoclastos do embasamento e raros moldes de possíveis clastos pelíticos incorporados ao fluxo (Fig. 7). O acamamento mergulha entre $30^{\circ}$ e $35^{\circ}$ para SSE.

\section{Gênese}

A origem destes depósitos está ligada a vulcanismo explosivo, com fluxos piroclásticos e deposição de fácies subaéreas (brechas e ignimbritos) nas margens da bacia e de fácies subaquosas decorrentes da queda de cinzas nas áreas submersas mais distais. Este vulcanismo provavelmente está relacionado à reativação frágil de lineamentos brasilianos que também originou o graben devoniano.

\section{Limites, espessura e área de ocorrência}

$\mathrm{Na}$ área-tipo, a unidade tem, no mínimo, oito metros (8 m) de espessura estimada, é tabular com acamamento irregular, aparentemente amalgamado. O limite inferior é não-conforme e o superior é dado pela superfície atual do terreno. O contato lateral é por falha com a Formação Piranhas e abrupto-conforme com a Formação Pilóes.

\section{Correlação bioestratigráfica e idade}

Por ser estéril em fósseis, a idade mínima desta unidade é inferida como eodevoniana devido à presença de fragmentos vulcânicos em amostras de calha do poço 1-PIL-1-PB, coletadas no intervalo sotoposto aos dos estratos do Devoniano Inferior, os quais têm níveis ricos em analcima e clorita que podem ser produtos de alteração de cinzas vulcânicas depositadas com os sedimentos devonianos (Silva I. 2014). 
Esta unidade também pode ser correlacionada ao ignimbrito reportado por Cordani et al. (1984), na base do poço 1-IZ1 - MA, interpretado como de idade siluriana ou mais antiga.

\section{Observaçóes}

Estudos de campo, faciológico, litogeoquímico e petrográfico são necessários para uma melhor caracterização das fácies vulcanoclásticas e da área de ocorrência.

\section{Ocorrência das unidades devonianas e suas relações estratais em superfície}

No quadrante noroeste do mapa geológico (Fig. 8A), as unidades devonianas afloram. Ao longo da falha de Brejo das Freiras, as formaçóes Pilóes e Triunfo e as brechas vulcânicas limitam-se com a Formação Piranhas.

No bloco alto da mesma falha, o limite da Formação Pilóes com o embasamento é não-conforme, embora localmente possa ser por falha, como interpretado a partir da sísmica (Figs. 4 e 8B). Aflora nos quadrantes $\mathrm{NO}$ e NE em contato gradacional-interdigitado com a Formação Triunfo, na cuesta alinhada à falha de Brejo das Freiras, e abrupto-conforme, com corpos isolados da mesma unidade, na borda norte do SgS.

O contato das brechas e ignimbritos (brecha vulcânica Poço da Jurema) com o embasamento é não-conforme. Com a Formação Piranhas, o contato se dá por falha, e com a Formação Pilóes é aparentemente abrupto-conforme, embora possa ser discordante se o evento vulcânico não for contemporâneo à sedimentação devoniana. Nos poços, estas vulcanoclásticas podem estar indiferenciadas na base da Formação Pilóes (Fig. 8B).

O limite das unidades devonianas com a Formaçáo Sousa é discordante, localmente angular, porém difícil de ser mapeado, em superfície, devido à cobertura de solo. No mapa está inferido com base em dados de afloramento, do relevo e de imagem de satélite.

\section{DISCUSSÃO}

No prefácio ao Léxico Estratigráfico do Brasil (Baptista et al. 1984), o geólogo Oscar Braun orienta sobre a criação de novas unidades estratigráficas, as quais devem atender aos requisitos e critérios codificados, além de promover necessariamente a simplificação do conhecimento geológico. A denominação deve ser corolário da existência inequívoca da unidade, a qual deve ser descrita e classificada de acordo com o método científico e a sistemática adequada.

Embora a existência de estratos devonianos na BRP esteja bem embasada em dados bioestratigráficos (Roesner et al. 2011), a proposta de novas unidades carece de reflexão mais aprofundada, mormente as implicaçóes no arcabouço estratigráfico local e regional.

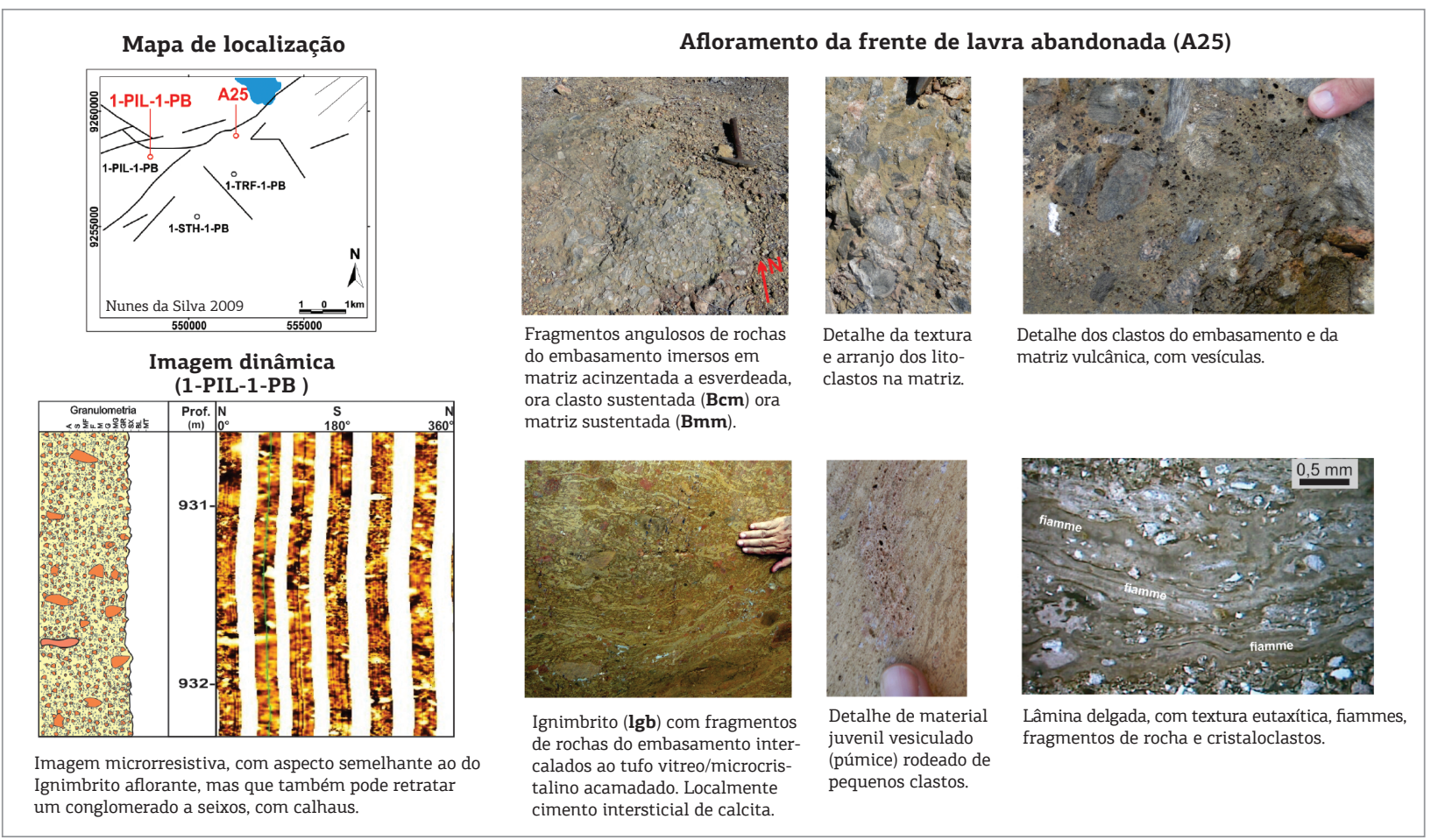

Figura 7. Características das brechas vulcânicas clasto-sustentadas (Bcm), matriz-sustentadas (Bmm) e ignimbritos (Igb). 
No âmbito local, o primeiro ponto a ser discutido trata da classificação litoestratigráfica dos conglomerados e brechas associados à porção basal da tectonossequência devoniana.

Formalmente descritos como parte da Formaçáo Antenor Navarro por Mabesoone e Campanha (1974), as brechas e conglomerados imaturos, localmente cimentados (silicificados), junto às bordas falhadas, também têm sido relacionados à Formação Piranhas (Barbosa Junior et al. 1986), como ocorre na área estudada, que abrange o Alto de Santa Helena e a borda falhada do

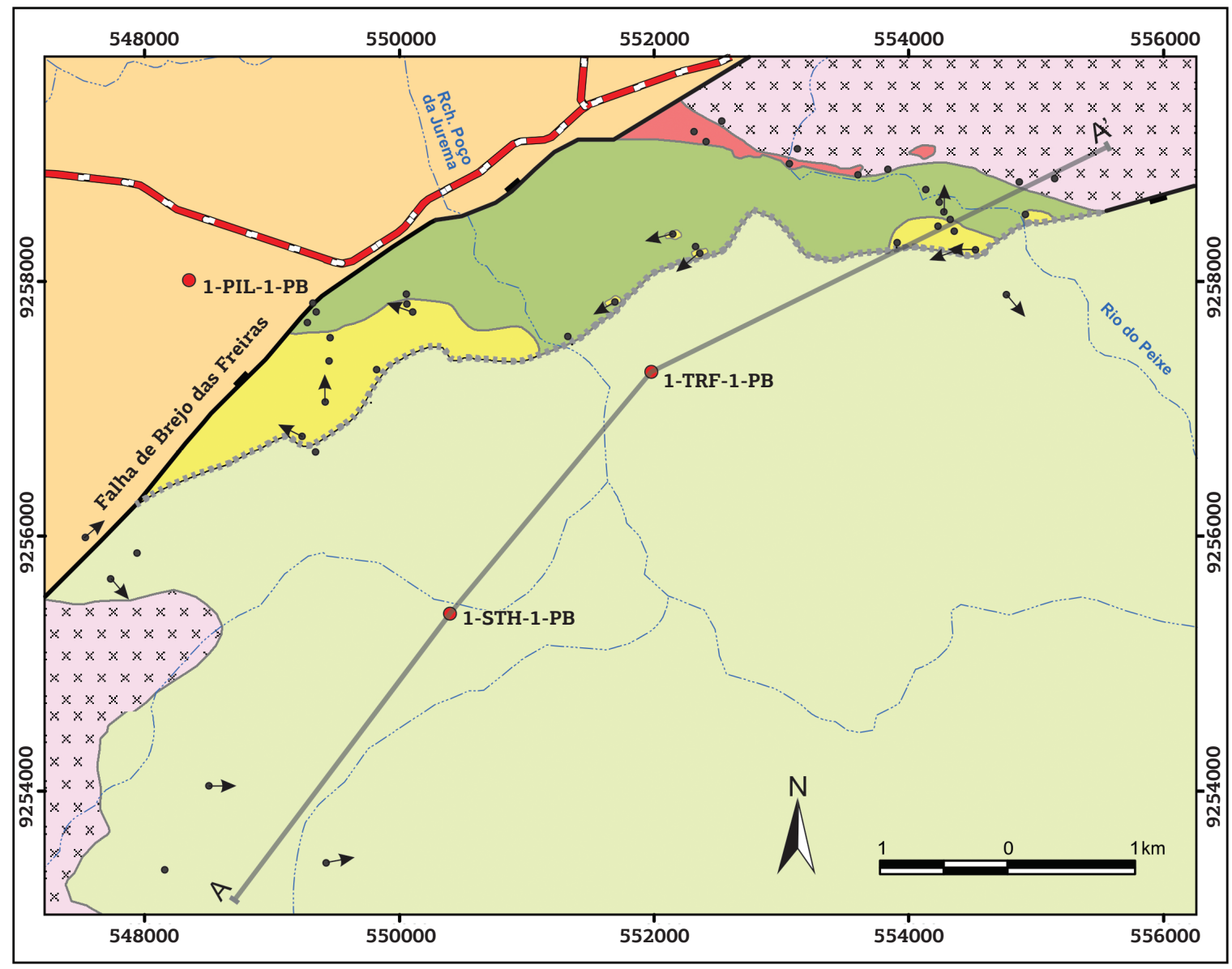

\begin{tabular}{|c|c|c|c|c|c|}
\hline \multicolumn{4}{|c|}{ Legenda } & \multicolumn{2}{|c|}{ Unidades Geológicas } \\
\hline & Ponto Visitado & $r_{i}$ & Drenagem & $\begin{array}{l}\text { Grupo Rio do Peixe } \\
\text { Cretáceo Inferior }\end{array}$ & $\begin{array}{l}\text { Grupo Santa Helena } \\
\text { Devoniano Inferior }\end{array}$ \\
\hline A & Paleocorrente & $\square$ & Rodovia & $\square$ Formação Piranhas & $\square$ Formação Triunfo \\
\hline & Poço BR & A $\quad A^{\prime}$ & Seção geológica & $\square$ Formação Sousa & $\square$ Formação Pilões \\
\hline \multicolumn{4}{|c|}{ Estrutural } & \multicolumn{2}{|c|}{ brecha vulcânica Poço da Jurema } \\
\hline ".." & Discordância & - & Falha normal & $x$ embasame & \\
\hline
\end{tabular}

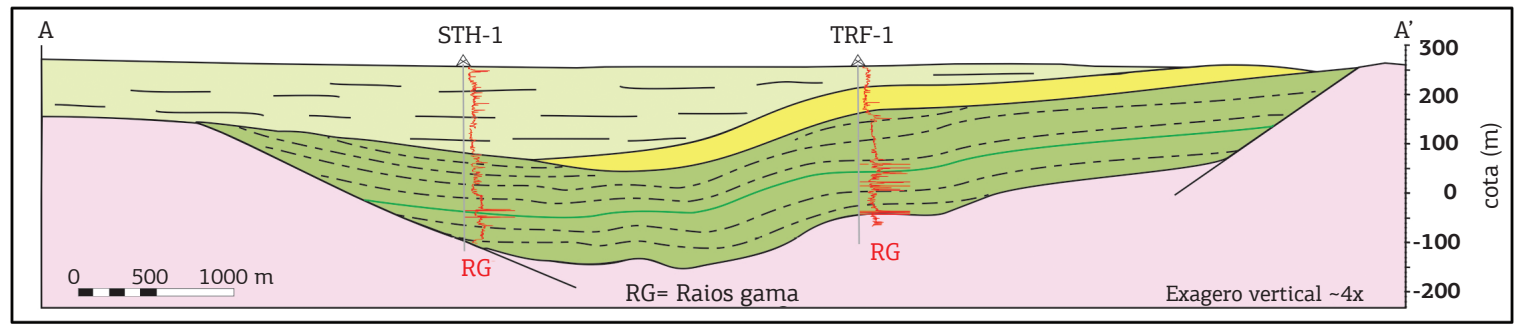

Figura 8. Mapa geológico e seção geológica AA', passando pelos poços STH-1 e TRF-1. 
SgBF-T (Sousa et al. 2007, Córdoba et al. 2008, Nunes da Silva 2009). Embora algumas destas brechas e ignimbritos associados tenham sido descritas como depósitos da Formação Rio Piranhas (Nunes da Silva 2009), esta interpretação está sendo revista, uma vez que as mesmas têm natureza vulcânica.

No perfil de imagem do poço 1-PIL-1-PB, são interpretadas brechas de tálus interdigitadas com a seção arenopelítica da Formação Pilóes, sobrepostas a conglomerados, arenitos conglomeráticos e rochas vulcanoclásticas, cujos fragmentos estấo presentes em amostras de calha próximas ao topo do embasamento. Ao considerar estas evidências de poço, conclui-se que há brechas vulcânicas depositadas durante o Eodevoniano ou, no mínimo, mais antigas.

Por certo, há brechas (sedimentares, vulcânicas ou de falha) e conglomerados, de diferentes idades, associados ao preenchimento da BRP. Cada caso deve ser avaliado com base nas características litológicas e nas relaçóes de contato destes litotipos com as unidades cretáceas ou devonianas, evitando-se o risco da generalização.

Outra questáo, com reflexo no arcabouço estratigráfico local, refere-se ao posicionamento dos arenitos estratificados e conglomerados intercalados (UL5 nas Figs. 2A e 2B) na Formação Triunfo, dentro da tectonossequência devoniana inferior, ou na Formaçáo Antenor Navarro (tectonossequência cretácea inferior), posto ainda não haver datação inequívoca para apoiar uma ou outra hipótese.

Os dados de poços, sismoestratigráficos e de afloramentos indicam uma discordância angular, entre a base da Formação Sousa e o topo da Formação Triunfo, cuja atitude do acamamento mantém continuidade com a da Formação Pilôes, além do contato gradacional-interdigitado entre estas duas unidades, no poço 1-PIL-1-PB (Figs. 2A e 5). Outro aspecto relevante, é que a espessura destes arenitos é praticamente a mesma nos poços 1-PIL-1-PB, perfurado na margem falhada do SgBF-T, e no 1-TRF-1-PB, perfurado na margem flexural do $\mathrm{SgS}$, o que sugere a deposição do sistema fluviodeltaico em um depocentro único. Além disso, os arenitos devonianos são arcóseos (Silva I. 2014) e os da Formação Antenor Navarro são quatzoarenitos (Costa 2010), o que sugere área-fonte e/ou contexto tectonossedimentar distintos para estas unidades.

No tocante às implicaçóes no âmbito regional, as unidades propostas podem ser confrontadas com as cronocorrelatas nas bacias paleozoicas mais próximas. A sedimentação pelitopsamítica do Grupo Santa Helena ocorreu em um graben de águas doces a salobras, com paleocorrentes orientadas para o quadrante $\mathrm{NO}$, sem continuidade deposicional com a sedimentação arenítica da parte superior do Grupo Serra Grande (Caputo \& Lima 1984, Santos \& Carvalho 2004) e nem com a parte inferior do Grupo Canindé (Vaz et al. 2007), na margem leste do mar epicontinental Parnaíba.

Nas duas bacias, há diferenças entre as unidades cronoequivalentes, tais como a ausência, na unidades da Bacia do Parnaíba, do intervalo com pelitos carbonosos, com forte anomalia radioativa, e do intervalo pelítico com influência vulcânica, com anomalia no perfil neutrão, ambos na Formação Pilóes.

$\mathrm{Na}$ Bacia do Jatobá, localizada a cerca de $90 \mathrm{~km}$ a sul da BRP, a Formação Tacaratu representa a sedimentação silurodevoniana ((Costa I. et al. 2007)). Da mesma firma, na Bacia do Araripe, a Formaçáo Cariri representa estratos do Ordoviciano Superior-Devoniano Inferior (Assine 2007). Não obstante estas unidades sejam afossilíferas, poderiam ser enquadradas em um mesmo contexto deposicional do Grupo Santa Helena.

A orientação média das paleocorrentes destas unidades eopaleozoicas, para N-NO (Assine 1994), é compatível com o rumo dos paleofluxos da Formação Triunfo para o quadrante NO. No entanto, nesta predominam arcóseos, com provável área-fonte do tipo bloco continental soerguido (rifte) a transicional (Silva I. 2014), ao passo que, nas outras unidades, a composiçáo é quartzoarenítica, subordinadamente subarcoseana a sublitarenítica, com proveniência de região cratônica estável, com alguma reativação de borda (Carvalho et al. 2010, Batista et al. 2011).

Mesmo considerando a área-fonte e gênese comuns para estas unidades, a Formação Triunfo, por ser arcoseana, teria pouca probabilidade de ter continuidade deposicional com as formaçóes Tacaratu e Cariri, pois foi depositada a jusante das mesmas. Portanto, deveria ser mais matura composicional e texturalmente. Embora as rochas vulcanoclásticas possam ter sido a fonte local para este aporte de feldspatos.

Diante do exposto, conclui-se ser válida a classificação litoestratigráfica proposta, pois discrimina unidades com características litológicas distintas entre si. Porém, são geneticamente relacionadas a uma mesma fase de subsidência mecânica devoniana, cujo registro preservado na área estudada pode ser apenas um relicto de um sistema mais amplo de grabens eodevonianos.

Estas novas unidades vêm simplificar o conhecimento atual da BRP, ao atribuir uma identidade própria aos estratos devonianos e às vulcanoclásticas associadas, o que possibilitará o seu reconhecimento e mapeamento na bacia e em outros sítios deposicionais da Província Borborema. 


\section{CONCLUSÕES}

A evolução tectonossedimentar da BRP é mais complexa do que se pensava. Pelo menos em dois semigrabens, ocorrem duas fases de subsidência mecânica e não apenas uma (eocretácea). O sítio da sedimentação sintectônica foi, provavelmente, um graben com significativo influxo de água doce, porém com períodos nos quais havia conexão com águas marinhas (mar Parnaíba), propiciando águas salobras em seu interior, semelhante ao que ocorre atualmente no mar báltico.

A tectonossequência devoniana inferior corresponde a um ciclo transgressivo-regressivo e, em termos litoestratigráficos, ao Grupo Santa Helena, com duas unidades: a Formação Pilóes (inferior), composta predominantemente por pelitos escuros (localmente oxidados), com analcima, e arenitos arcoseanos, localmente cloríticos, associados com brechas, conglomerados e vulcanoclásticas na porção basal, e a Formação Triunfo (superior), na qual predominam arenitos cinza-esbranquiçados, arcoseanos, em parte conglomeráticos, caulínicos, com estratificações cruzadas, localmente com intercalaçôes de conglomerados e raros pelitos e arenitos finos a muito finos.

A Formação Pilóes foi depositada a partir de fluxos gravitacionais de sedimentos e de material vulcanoclástico, na porção distal de leques deltaicos e deltas de granulação grossa, em um graben de águas salobras a doces, o qual foi assoreado por depósitos fluviodeltaicos do tipo entrelaçado correspondentes à Formação Triunfo.
Estas unidades têm características litológicas, gênese e idade diferentes das demais unidades litoestratigráficas formais da BRP, das quais estão separadas por uma discordância, com um hiato de aproximadamente 265 milhóes de anos. Da mesma forma, não são compatíveis com as unidades potencialmente cronocorrelatas das bacias do Parnaíba, Araripe e Jatobá.

Ignimbritos e brechas coignimbríticas afloram na margem norte da bacia. Fragmentos vulcânicos e produtos interpretados como alteração diagenética de vidro vulcânico (analcima e clorita), associados à Formação Pilóes, sugerem que o evento piroclástico seja contemporâneo à sedimentaçáo eodevoniana ou mais antigo.

A existência de um graben eodevoniano na BRP associado a vulcanismo, indica que a evolução da bacia é poli-histórica e que as zonas dúcteis brasilianas sofreram reativação frágil durante o Eopaleozoico, reforçando a existência de grabens coevos ou precursores de algumas sinéclises paleozoicas.

\section{AGRADECIMENTOS}

O primeiro autor agradece à PETROBRAS, pela liberação dos dados e permissão de publicação dos resultados da pesquisa de mestrado, e à Universidade Federal do Rio Grande do Norte (UFRN) pelo seu acolhimento no Programa de Pós-Graduação em Geodinâmica e Geofísica. Os autores também são gratos aos revisores ad hoc pelos comentários e sugestôes.

\section{REFERÊNCIAS}

Albuquerque J.P.T. 1970. Inventário Hidrogeológico do Nordeste. Folha n 15. Recife, SUDENE, Divisão de Documentação, 187 p.

Antunes A.F., Andrade P.R.O., Jardim de Sá E.F., Lins F.A.P.L., Silva F.C.A., Sousa D.C., Córdoba V.C. 2007. Estilo tectônico do rifte na Bacia do Rio do Peixe. In: $22^{\circ}$ Simpósio de Geologia do Nordeste. Natal, Boletim 20, p. 218.

Antunes A.F., Jardim de Sá E.F., Lins F.A.P.L., Córdoba V.C., Sousa D.C., Nunes da Silva A. 2009. Tectonic framework of the Rio do Peixe Basin (Northeast Brazil). In: $11^{\text {th }}$ International Congress of the Brazilian Geophysical Society. Salvador, Extended Abstracts, p. 1-6.

Arai M. 2006. Revisão estratigráfica do Cretáceo Inferior das bacias interiores do Nordeste do Brasil. Geociências, 25(1):7-15.

Assine M.L. 1994. Paleocorrentes e paleogeografia na Bacia do Araripe, Nordeste do Brasil. Revista Brasileira de Geociências, 24(4):223-232

Assine M.L. 2007. Bacia do Araripe. Boletim de Geociências da Petrobras, 15(2):371-389.

Baptista M.B., Braun O.P.G., Campos D.A. (eds). 1984. Léxico Estratigráfico do Brasil. Brasília, Departamento Nacional da Produção Mineral, 560 p.
Barbosa Junior W.V, Silva I.B., Santos R.C., Pimentel C.A.C., Nóbrega V.A, Mabesoone J.M. 1986. Revisão geológica da parte oriental da Sub-bacia de Sousa (Bacia do Rio do Peixe). In: $34^{\circ}$ Congresso Brasileiro de Geologia. Goiânia, Anais, v. 1, p. 208-220.

Batista Z.V., Valença L.M., Neumann V.H., Silva S.M.A., Vieira M.M. 2011. Caracterização petrográfica dos arenitos da Formação Mauriti, Bacia do Araripe, Nordeste do Brasil. Estudos Geológicos, 21(1):41-58.

Braun O.P.G. 1969. Geologia da Bacia do Rio do Peixe Nordeste do Brasil. Departamento Nacional da Produção Mineral/PROSPEC S.A., 23 p. (Relatório interno).

Caputo M.V. \& Lima E.C. 1984. Estratigrafia, idade e correlação do Grupo Serra Grande Bacia do Parnaíba. In: $33^{\circ}$ Congresso Brasileiro de Geologia. Rio de Janeiro, Anais, v. 2, p. 740-753.

Caputo M.V., Rodrigues R. Vasconcelos D.N.N. 1972. Nomenclatura estratigráfica da Bacia do Amazonas: histórico e atualização. In: $26^{\circ}$ Congresso Brasileiro de Geologia. Belém, Anais, v. 3, p. 35-46.

Carvalho I.S. \& Leonardi G. 1992. Geologia das Bacias de Pombal, Sousa, Uiraúna-Brejo das Freiras e Vertentes (Nordeste do Brasil). Anais da Academia Brasileira de Ciências, 64(3):231-252. 
Carvalho R.R., Neumann V.H., Fambrini G.L., Vieira M.M., Rocha D.E.G.A. 2010. Origem e proveniência da Sequência Siliciclástica inferior da Bacia do Jatobá. Estudos Geológicos, 20(2):113-127.

Conde Blanco, A.J.P. 2013. Modelagem estrutural física de semigráben ortogonais e oblíquos à distensão regional: Influência da trama do embasamento e comparação com análogo do Nordeste Brasileiro. MS Dissertation, Programa de Pós-Graduação Geodinâmica e Geofísica, Universidade Federal do Rio Grande do Norte, Natal, 65p.

Cordani U.G., Neves B.B.B., Fuck R.A., Porto R., Thomaz Filho A., Cunha F.M.B. 1984. Estudo preliminar de integração do Pré-Cambriano com os eventos tectônicos das bacias sedimentares brasileiras, Ciência Técnica Petróleo, 15:1-70.

Córdoba V.C., Antunes A.F., Jardim de Sá E.F., Nunes da Silva A., Sousa D.C., Lins F.A.P.L. 2008. Análise estratigráfica e estrutural da Bacia do Rio do Peixe Nordeste do Brasil: integração de dados a partir do levantamento sísmico pioneiro 0295_rio_do_peixe_2d. Boletim de Geociências da Petrobras, 16(1):53-68.

Costa A.B.S. 2010. Diagênese e proveniência dos arenitos da Tectonossequência Rifte nas bacias do Rio do Peixe e Araripe, NE do Brasil. MS Dissertation, Programa de Pós-Graduação Geodinâmica e Geofísica, Universidade Federal do Rio Grande do Norte, Natal, 96 p.

Costa I.P., Bueno G.V., Milhomem P.S., Lima e Silva H.S.R., Kosin M.D. 2007. Sub-bacia de Tucano Norte e Bacia de Jatobá. Boletim de Geociências da Petrobras, 15(2):445-453.

Costa M.T. \& Branco J.J.R. 1961. Roteiro para a excursão Belo Horizonte - Brasília. In: Branco, J.J.R. (ed.). Contribuição ao $14^{\circ}$ Congresso Brasileiro de Geologia. Belo Horizonte, Instituto de Pesquisas Radioativas, Publicação, 15:9-25.

Costa P.R.C., Jardim de Sá E.F. Andrade, P.R.O., Lins F.A.P.L., Antunes A.F., Alves da Silva F.C., Schots H.A. 2007. Arcabouço estrutural da Bacia do Rio do Peixe. In: $11^{\circ}$ Simpósio Nacional de Estudos Tectônicos. Natal, Anais, p. 71

Costa W.D. 1964. Nota preliminar da geologia da Bacia do Rio do Peixe. Boletim do Departamento de Geologia, 4:47-50.

Cunha P.R.C., Melo J.H.G., Silva O.B. 2007. Bacia do Amazonas. Boletim de Geociências da Petrobras, 15(2):227-251.

Françolin J.B.L. \& Szatmari P. 1987. Mecanismo de rifteamento da porção oriental da margem norte brasileira. Revista Brasileira de Geociências, 17(2):196-207.

Françolin J.B.L., Cobbold P.R., Szatmari P. 1994. Faulting in the Early Cretaceous Rio do Peixe basin (NE Brazil) and its significance for the opening of the Atlantic. Journal of Structural Geology, 16(5):647-661.

Galeão da Silva G., Lima M.I.C., Andrade A.R.F., Issler R.S.; Guimarães, G. 1974. Geologia das folhas SB.22 Araguaia e parte da folha SC.22 Tocantins.. In: BRASIL, Departamento Nacional da Produção Mineral. Projeto RADAM, Levantamento de Recursos Naturais. Rio de Janeiro, p. 1-143.

Ghignone J.I., Couto E.A., Assine, M.L. 1986. Estratigrafia e estrutura das bacias do Araripe, Iguatu e Rio do Peixe. In: $34^{\circ}$ Congresso Brasileiro de Geologia, Goiânia, Anais, v. 1, p. 271-286.

Johnson J.G. \& Murphy M.A. 1984. Time-rock model for SiluroDevonian continental shelf, western United States Geological Society of America Bulletin, 95(5):1349-1359.

Lima M.R. 1990. Estudo palinológico de sedimentos da Bacia de Icó, Cretáceo do Estado do Ceará, Brasil. Boletim do Instituto de Geociências-USP, Série Científica, 21:35-46.

Lima M.R. \& Coelho M.P.C.A. 1987. Estudo palinológico da sondagem de Lagoa do Forno Bacia do Rio do Peixe Cretáceo do Nordeste do Brasil. São Paulo. Boletim do Instituto de Geociências-USP, Série Científica, 18:67-83.
Lima Filho M.F. 1991. Evolução Tectono-Sedimentar da Bacia do Rio do Peixe (PB). MS Dissertation, Departamento de Geologia, Universidade Federal de Pernambuco, Recife, 99 p.

Mabesoone J.M. 1972. Sedimentos do Grupo Rio do Peixe (Paraíba). In: 26 Congresso Brasileiro de Geologia, Belém, Boletim, v. 1: p. 236.

Mabesoone J.M. \& Campanha V.A. 1973/1974. Caracterizacão estratigráfica dos Grupos Rio do Peixe e Iguatu. Estudos Sedimentológicos, 3/4:21-41.

Matos R.M.D. 1992. The Northeast Brazilian Rift System. Tectonics, 11(4):766-791.

Matos R.M.D. 1999. Hystory of the Northeast Brasilian Rift Systems: kinematic implications for the break-up between Brazil and West Africa. In: Cameron N.R., Bate R.H., Clure, V.S. (eds.) The Oil and Gas Habitats of the South Atlantic. London, Geological Society, Special Publications, 153:55-73.

Medeiros V.C., Amaral C.A., Rocha D.E.G.A., Santos R.B. 2005. Mapa geológicodos Estados da Paraíba, Rio Grande do Norte e Ceará, escala 1:250.000. Programa Geologia do Brasil - PGB. Sousa. Folha SB.24Z-A.. Recife, CPRM

Miall A.D. 1990. Principles of Sedimentary Basin Analysis. New York, Springer-Verlag, $668 \mathrm{p}$

Milani E.J., Melo, J.H.G., Souza P.A., Fernandes L.A., França A. B. 2007. Bacia do Paraná. Boletim de Geociências da Petrobras, 15(2):265-287.

Miranda L.L.F. \& Silva J.G. 1978. Estratigrafia e mineralizações do Grupo Bambuí na Serra do Ramalho. In: $30^{\circ}$ Congresso Brasileiro de Geologia, Recife, Anais, v. 6, p. 2534-2547.

Moraes L.J. 1924. Serras e montanhas do Nordeste. Ministério da Viação e Obras Públicas, Inspectoria de Obras contra as Seccas. Geologia. Rio de Janeiro, Série I. D., 58. (2a ed. Coleção Mossoroense, Fundação Guimarães Duque, Escola Superior de Agricultura de Mossoró, 35, 1997) p. 43-49

North American Commission on Stratigraphic Nomenclature (NACSN). 2005. North American Stratigraphic Code. American Association of Petroleum Geologists Bulletin, 89(11):1547-1591.

Nunes da Silva A. 2009. Arquitetura litofácies e evolução tectonoestratigráfica da Bacia do Rio do Peixe Nordeste do Brasil. MS Dissertation, Programa de Pós-Graduação Geodinâmica e Geofísica, Universidade Federal do Rio Grande do Norte, Natal, 108p.

Petri S., Coimbra A.M., Amaral G., Ojeda y Ojeda H., Fúlfaro V.J., Ponçano W.L. 1986a. Código Brasileiro de Nomenclatura Estratigráfica. Revista Brasileira de Geociências, 16(4):372-376.

Petri S., Coimbra A.M., Amaral G., Ponçano W.L. 1986b. Guia de Nomenclatura Estratigráfica. Revista Brasileira de Geociências, 16(4):376-415.

Ponte F.C. 1992. Origem e evolução das pequenas bacias cretáceas do nordeste do Brasil. In: $2^{\circ}$ Simpósio sobre as Bacias Cretácicas do Brasil. Rio Claro, p. 55-58.

Regali M.S.P. 1990. Biocronoestratigrafia e paleoambiente do Eocretáceo das bacias do Araripe (CE) e Rio do Peixe PB), NE-Brasil. In: $1^{\circ}$ Simpósio sobre a Bacia do Araripe e Bacias Interiores do Nordeste, Crato, Atas, p. 163-172.

Roesner H.E., Lana C.C., Le Herissé A., Melo J.H.G. 2011. Bacia do Rio do Peixe (PB). Novos resultados biocronoestratigráficos e paleoambientais. In: Carvalho I.S., Srivastava N.K., Strohschoen Jr O., Lana C.C. (eds.) Paleontologia: Cenários de Vida, 3. Rio de Janeiro. Interciência, p. 135-141. 
Rubinstein C., Melo J.H.G., Steemans P. 2005. Lochkovian (earliest Devonian) miospores from the Solimões Basin, northwestern Brazil. Review of Paleobotany and Palinology, 133:91-113.

Santos M.E.C.M. \& Carvalho M.S.S. 2004. Paleontologia das bacias do Parnaỉba, Grajaú e São Luís. Programa Levantamentos Geológicos Básicos do Brasil, CPRM. Serviço Geológico do Brasil DIEDIG/DEPAT, Rio de Janeiro. CPRM/DIEDIG/DEPAT. (CD-ROM). 212 p.

Schneider R.L., Mühlmann H., Tommasi E., Medeiros A., Daemon R.F. Nogueira A.A. 1974. Revisão estratigráfica da Bacia do Paraná. In: $28^{\circ}$ Congresso Brasileiro de Geologia, Porto Alegre, Anais, v. 1, p. 41-65.

Scherer C.M.S., Córdoba V.C., Sousa D.C., Jardim de Sá E.F. 2007. Associações de fácies típicas de sitemas fluviais distributários na Bacia do Rio do Peixe, NE do Brasil. In: 22 Simpósio de Geologia do Nordeste. Natal, Boletim, p. 7.

Sénant J. \& Popoff M. 1991. Early Cretaceous extension in northeast Brazil related to the South Atlantic opening. Tectonophysics. 198:35-46.

Silva I.T. 2014. Evolução diagenética e caracterização dos reservatórios da seção devoniana na Bacia do Rio do PeixeNordeste do Brasil. MS Dissertation, Programa de Pós-Graduação em Ciência e Engenharia de Petróleo, Universidade Federal do Rio Grande do Norte, Natal, 144 p.
Silva J.G.F. 2014. Análise estratigráfica de subsuperfície do Devoniano da Bacia do Rio do Peixe, Nordeste do Brasil. MS Dissertation, Programa de Pós-graduação em Geodinâmica e Geofísica, Universidade Federal do Rio Grande do Norte, Natal, 194 p.

Sousa D.C., Córdoba V.C. Jardim de Sá E.F. Scherer C.M.S., Antunes A.F., Nunes da Silva A., Andrade P.R.O. 2007. Arquitetura deposicional da Bacia do Rio do Peixe, NE do Brasil. In: 22 Simpósio de Geologia do Nordeste. Natal, Boletim 20, p. 5

Tinoco I.M. \& Katoo I. 1975. Conchostraceos da Formação Sousa, Bacia do Rio do Peixe, Estado da Paraíba. In: $7^{\circ}$ Simpósio de Geologia do Nordeste. Fortaleza, Boletim, p. 135-147.

Vaz P.T., Rezende N.G.A.M., Wanderley Filho J.R., Travassos W.A.S. 2007. Bacia do Parnaíba. Boletim de Geociências da Petrobras, 15(2):253-263.

Wanderley Filho J.R., Eiras J.F., Vaz P.T. 2007. Bacia do Solimões. Boletim de Geociências da Petrobras, 15(2):217-225.

Zalán P.V. \& Silva, P.C.R. 2007. Bacia do São Francisco. Boletim de Geociências da Petrobras, 15(2):561-570.

Arquivo digital disponível on-line no site www.sbgeo.org.br 